\title{
1 Effects of an experimental increase in flow intermittency on an alpine stream
}

2 Andre R. Siebers ${ }^{1,4, \dagger}$, Amael Paillex ${ }^{1,5}$, Benjamin Misteli ${ }^{1,2,6}$, Christopher T. Robinson ${ }^{1,3}$

$4{ }^{1}$ Department of Aquatic Ecology, Eawag, Swiss Federal Institute of Aquatic Sciences and

5 Technology, Überlandstrasse 133, 8600 Dübendorf, Switzerland

6

$7 \quad{ }^{2}$ Department of Environmental Systems Science, ETH Zürich, 8092 Zürich, Switzerland

$9 \quad{ }^{3}$ Institute of Integrative Biology, ETH Zürich, 8092 Zürich, Switzerland

10

$11{ }^{4}$ Current address: Centre for Freshwater Ecosystems, La Trobe University, Wodonga, VIC 3690,

12 Australia

$13{ }^{5}$ Current address: ECOTEC Environment SA, 1203 Geneva, Switzerland

$14{ }^{6}$ Current address: ECOBIO, UMR 6553 CNRS, Université de Rennes 1, Rennes, France

15 Email addresses: andre.siebers@ outlook.com, amael.paillex@ hispeed.ch,

16 benjamin.misteli@univ-rennes1.fr, robinson@eawag.ch

17

$18 \dagger$ Author for correspondence: andre.siebers@ outlook.com

This document is the accepted manuscript version of the following article:

Siebers, A. R., Paillex, A., Misteli, B., \& Robinson, C. T. (2020). Effects of an experimental increase in flow intermittency on an alpine stream. Hydrobiologia. https://doi .org/10.1007/s10750-020-04350-7 


\section{Abstract}

20 Flow intermittency occurs naturally in alpine streams. However, changing rainfall patterns and

21 glacier retreat are predicted to increase the occurrence of flow intermittency in alpine catchments,

22 with largely unknown effects on ecosystem structure and function. We conducted a flow

23 manipulation experiment within a headwater stream of Val Roseg, a glacierized alpine

24 catchment, to determine the effects of increased flow intermittency on aquatic

25 macroinvertebrates, periphyton, benthic organic matter, and trophic structure. Compared to an

26 adjacent reference channel, an increase in flow intermittency reduced macroinvertebrate density,

27 taxa richness, and the proportion of rheophilic taxa. Density and richness remained low in the

28 manipulated channel after resumption of natural flow. Flow intermittency did not affect organic

29 matter standing stocks, but increased assimilation of periphyton by aquatic macroinvertebrates.

30 Predation on aquatic invertebrates by riparian spiders also increased. We attribute many of these

31 patterns to the timing of drying, which likely excluded summer-growing cohorts of rheophilic,

32 aerial dispersers. This study suggests that reductions in summer glacial melt and rainfall events

33 might increase flow intermittency and lead to fundamental changes in diversity and function of

34 alpine fluvial networks.

36 Keywords: glacial, macroinvertebrates, stable isotopes, drift, biofilm, benthic organic matter 


\section{Introduction}

38 Alpine streams are seasonal ecosystems. In particular, the contribution of different water sources

39 to streams varies across both space and time in alpine fluvial networks (Malard et al., 1999;

40 Brown et al., 2003; Robinson et al., 2016a). Relative contributions of snowmelt, glacial melt,

41 groundwater, and rainfall drive wide variation in the physical and chemical environment of alpine

42 streams and, as a consequence, the structure and function of benthic ecosystems (Ward, 1994;

43 Brown et al., 2003). Alpine landscapes also exhibit high gradients, shallow aquifers, and limited

44 sub-surface storage that contribute to flashy flow regimes linked to seasonality in glacial

45 meltwaters and major rain events (Malard et al., 2000; Robinson \& Matthaei, 2007; Robinson et

46 al., 2016a). Several recent studies have documented widespread, seasonal flow intermittency

47 among alpine headwaters (Robinson et al., 2016a; Gabbud et al., 2019; Paillex et al., 2020).

Intermittent alpine streams dry most widely during winter freeze periods, but summer and

49 autumn drying periods are also common (possibly $40 \%$ of headwater networks: Paillex et al.,

50 2020). However, current climate models predict increased temperatures and decreased rainfall

51 during summer for alpine regions (Horton et al., 2006; Zemp et al., 2006; IPCC, 2014). While

52 increasing summer temperatures might increase glacial melt contributions to streams in the short

53 term, reductions in glacier volume will ultimately decrease this source of flow (Huss \& Hock,

54 2018). Reductions in glacial melt and rainfall likely will increase flow intermittency in streams

55 during summer and early autumn (Paillex et al., 2020). General expectations of glacial melt

56 reductions are well documented for streams in terms of temperature and channel stability, with

57 relatively less consideration of drying events (Brown et al., 2017; Milner et al., 2017).

58 Comparatively, we thus have little understanding of how flow intermittency might affect the

59 ecology of alpine fluvial networks. 
Reductions in flow associated with decreases in glacial melt initially warm and stabilize

61 alpine stream flows, which leads to increases in benthic production (Cauvy-Fraunié et al., 2016).

62 Further, many rheophilic taxa may be replaced by generalist species more tolerant of low flow

63 conditions (Milner et al., 2009; Cauvy-Fraunié et al., 2016). Indeed, rheophilic species may be

64 quite sensitive to the onset of drying events (Piano et al., 2019a). Macroinvertebrates inhabiting

65 alpine streams can be highly resistant to low temperatures, high turbidity, and unstable channels

66 (Hotaling et al., 2017), but have low resistance to low flows and desiccation (Piano et al., 2019a).

67 Here, resilience mechanisms such as drift (Doretto et al., 2019) and facultative use of the

68 hyporheos (Malard et al., 2003a; b) are common. Further, many alpine aquatic insects disperse

69 aerially as adults (Cauvy-Fraunié et al., 2015; Alther et al., 2019) and can quickly recolonize

70 intermittent streams upon rewetting (Shama et al., 2011). Drying may thus reduce

71 macroinvertebrate densities and richness sharply, but recovery after drying could be rapid (Lake,

72 2003).

The function of benthic ecosystems also likely changes after drying. Coarse particulate

74 organic matter quality is reduced in channels that dry through reduced leaching and breakdown

75 by microbes and invertebrates (Datry et al., 2018). Alpine macroinvertebrate assemblages consist

76 of many generalist grazers, gatherers, and omnivorous taxa, and thus exhibit high dietary

77 flexibility across alpine environmental gradients (Zah et al., 2001; Fell et al., 2017; Piano et al.,

78 2019b). Benthic macroinvertebrates in increasingly intermittent alpine streams may thus shift

79 their diets to include a greater proportion of autochthonous resources (Siebers et al., 2019),

80 thereby reducing the ecological niche of grazers (Piano et al., 2019b). Flow intermittency has

81 been shown to alter species turnover (Gabbud et al., 2019), population genetic structure (Shama

82 et al., 2016), and carbon cycling (Harjung et al., 2019) in alpine streams. Although these studies 
83 suggest flow intermittency to be a key driver of ecological processes in alpine streams, more field

84 experiments are required to elucidate the mechanistic factors of influence (e.g., Cauvy-Fraunié et

85 al., 2016; Doretto et al., 2019).

86 Here, we conducted an experimental flow manipulation in an alpine stream using a

87 before-after-control-impact (BACI) design. Flow was manipulated in a natural stream to simulate

88 the onset of summer drying periods in an otherwise only winter-drying alpine stream (Paillex et

89 al., 2020). Our first objective (i) was to compare differences in the density and composition of

90 benthic macroinvertebrates between the manipulated stream and an adjacent reference channel, in

91 the periods before, during and after the flow manipulation. We predicted that the density and

92 richness of macroinvertebrates would be lower in the manipulated channel during the

93 manipulation, rheophilic species in particular, but that recovery would occur following

94 resumption of natural flow (i.e., within 2 months, Larned et al., 2010). Our second objective (ii)

95 was to compare differences between the channels in benthic organic matter (CPOM and

96 periphyton) density and quality, as well as the estimated dietary proportions of aquatic

97 macroinvertebrates and predatory riparian invertebrates. We predicted that terrestrial organic

98 matter densities would be higher in the manipulated channel during the flow manipulation, but be

99 lower in quality, thus shifting the trophic base of benthic and riparian food webs towards aquatic

100 sources both during and after the flow manipulation. We discuss our results in the context of

101 future climate predictions for alpine regions.

\section{Material and Methods}

\section{Catchment and study channels}


104 Val Roseg is a glacierized valley within the Bernina massif of the eastern Swiss Alps $\left(46^{\circ} 42^{\prime} \mathrm{N}\right.$,

$1059^{\circ} 86^{\prime} \mathrm{E}$ ) (Ward \& Uehlinger, 2003). Flow regimes are driven by seasonally and topographically

106 complex combinations of glacial meltwater, rainfall, and snowmelt (Malard et al., 2005). Glacial

107 meltwater primarily feeds a second-order braided river with numerous headwater tributaries

108 draining valley side-slopes. Up to $90 \%$ of headwater streams in the fluvial network are

109 intermittent due to high gradients, shallow aquifers, and seasonal and spatial variation in water

110 sources (Robinson et al., 2016a; Paillex et al., 2020).

111 A naturally winter-drying headwater stream was chosen for the experiment based on prior

112 surveys and measurements of flow intermittency (Robinson et al. 2016a, Paillex et al., 2020). The

113 stream originates as a single channel around $650 \mathrm{~m}$ upstream of the experimental section where it

114 then splits naturally into two channels for around $350 \mathrm{~m}$ before converging back into a single

115 channel again. The study reaches (100 $\mathrm{m}$ in length) were located ca. $200 \mathrm{~m}$ downstream of where

116 the channel divides. The study reaches averaged 10-15 m apart and were similar in altitude (2041

117 m a.s.1.), slope (1.2 ${ }^{\circ}$ ) and vegetation (scattered small trees - Larix decidua, Pinus cembra, Alnus

118 viridis; shrubs - Juniperus communis subsp. alpina; and grasses and sedges - Festuca spp.,

119 Carex spp.) (Fig. 1).

120 Flow manipulation and measurement

121 The presence of surface water in each channel was measured using HOBO Pendant

122 Temperature/Light 64K data loggers (Onset Computer Corporation, Bourne, MA, USA) modified

123 to record electrical resistance and temperature (Chapin et al., 2014; Paillex et al., 2020). The

124 loggers were originally designed to record light intensity, but were modified to include external

125 electrodes connected to the light sensor contact pads. Consequently, the sensor records and

126 outputs relative electrical resistance as Lux (original units of light intensity). Lux readings are 
127 linearly correlated with electrical conductivity up to ca. $1000 \mu \mathrm{S} / \mathrm{cm}$ (Chapin et al., 2014). Zero

128 readings thus indicate absence of liquid water in channels (Paillex et al., 2020). Temperature

129 readings record the temperature of the medium at the time (water, air or ice). Loggers were

130 installed in the thalweg of each stream some months prior to the first sampling occasion, and

131 recorded hourly the presence and absence of surface water as well as temperature. Loggers were

132 removed briefly for maintenance in October 2018, but otherwise recorded data during the entire

133 experimental period.

134 A temporary flow diversion (dam) was installed on 5 June 2018 upstream of the sampling

135 reaches that diverted flow from entering one of the channels (Fig. 2). The flow manipulation

136 reduced discharge in this 'manipulation' channel (MC) directly downstream from the diversion

137 from $0.01 \mathrm{~m}^{2} \mathrm{~s}^{-1}$ pre-manipulation (Fig. 1c) to $0 \mathrm{~m}^{2} \mathrm{~s}^{-1}$ (Fig. 1d). Local bank storage, hyporheic

138 upwellings, and rainfall events continued to provide flow at various points further down the MC

139 (pers. obs., the authors), but the diversion eventually caused an increase in flow intermittency in

140 the channel (Fig. 2d). The 'reference' channel (RC) continued flowing both before (Fig. 1a) and

141 during (Fig. 1b) the manipulation. The flow diversion was removed on 20 September 2018, after

142 which the MC quickly resumed surface flow (Fig. 2d). The experiment thus included three

143 distinct measurement periods: 2 months from snowmelt until the flow manipulation (April to

144 June), 3 months of flow manipulation over summer and early autumn (June to September), and 2

145 months from removal of the manipulation until snow cover (September to November).

146 Sample collection and analysis

147 Sampling was conducted during the snow-free period monthly from May (prior to manipulation)

148 to November 2018 in both RC and MC (Fig. 2). We conducted two additional samplings on 30

149 August and 20 September to further characterize the flow manipulation period. When surface 
150 water was present, water temperature and electrical conductivity were measured on each site visit

151 with a WTW-3110 portable meter (Weilheim, Germany) for cross-validation with logger

152 readings. Water samples for chemical analysis were collected in triple-rinsed $0.5 \mathrm{~L}$ polypropylene

153 bottles without headspace, and stored at $4{ }^{\circ} \mathrm{C}$ for transport to the laboratory. Analyses were

154 conducted for alkalinity, $\mathrm{pH}$, dissolved organic carbon (DOC), total nitrogen (TN), nitrate $\left(\mathrm{NO}_{3^{-}}\right.$

$155 \mathrm{~N})$, total phosphorus $(\mathrm{TP})$, soluble reactive phosphate $\left(\mathrm{SRP} ; \mathrm{PO}_{4}-\mathrm{P}\right)$, and silicate $\left(\mathrm{H}_{4} \mathrm{SiO}_{4}\right)$ after

156 Tockner et al., (1997).

Benthic macroinvertebrates were collected using a Hess sampler (mesh size: $250 \mu \mathrm{m}$;

158 area: $0.0425 \mathrm{~m}^{2}$ ) at 3 to 5 representative locations along the $100 \mathrm{~m}$ study reach of each stream.

159 When surface water was flowing, samples were collected by disturbing the loosely consolidated

160 cobbles composing the streambed $(10 \mathrm{~cm}$ depth) within the Hess sampler for 10 seconds. When

161 the MC lacked surface water, we collected samples by excavating the dry streambed to the same

162 depth of $10 \mathrm{~cm}$, within the same area as a Hess sampler. Samples were elutriated in the field to

163 remove inorganic particles and stored in $80 \%$ ethanol until analysis in the laboratory.

164 In the laboratory, macroinvertebrates were hand-picked from each sample using a

165 dissecting microscope at 10x magnification. Many individuals were too small to identify

166 confidently to genus, and most families were represented by $\leq 3$ functionally similar genera (e.g.

167 Baetis spp. for Baetidae, Dictyogenus spp. and Isoperla spp. for Perlodidae). Macroinvertebrates

168 were therefore identified to the lowest common, practical taxonomic level (family for insects,

169 order for non-insects) and counted. Identification followed Tachet et al., (2010) with additional

170 reference for Plecoptera (Lubini et al., 2012), Trichoptera (Waringer \& Graf, 2011),

171 Ephemeroptera (Bauernfeind \& Humpesch, 2001), Coleoptera (Lucht, 1998) and Diptera

172 (Eiseler, 2010). The remaining material from each benthic sample was air-dried at $60^{\circ} \mathrm{C}$, 
173 weighed, combusted at $500^{\circ} \mathrm{C}$ for $4 \mathrm{~h}$, and reweighed to provide an estimate of coarse (> 250

$174 \mu \mathrm{m})$ benthic organic matter (BOM) as ash-free dry mass (AFDM). While we did not measure the 175 finest fraction of $\mathrm{BOM}(<250 \mu \mathrm{m})$, personal observations suggested that fine particulate matter 176 within both streams was largely inorganic.

Periphyton biomass was collected by randomly collecting 5 cobbles from each study

178 reach on each visit. Periphyton was removed from the top of each stone by scrubbing with a wire

179 brush and rinsing with stream water. The area scrubbed from each stone was measured, and an

180 aliquot of the periphyton suspension was filtered through a pre-combusted glass fiber filter

181 (Whatman GF/F). The filter was air-dried at $60^{\circ} \mathrm{C}$, weighed, combusted at $500^{\circ} \mathrm{C}$ for $4 \mathrm{~h}$, and 182 reweighed to measure AFDM.

183 Samples for isotope analysis were collected along the $100 \mathrm{~m}$ study reach of each stream.

184 Aquatic macroinvertebrates were collected by repetitive kick-sampling (mesh size: $250 \mu \mathrm{m}$ ) at

185 several sites along each reach to include all substrate types present (cobbles, sediment, mosses).

186 Aquatic macroinvertebrates were handpicked from samples and immediately sorted into $50 \mathrm{~mL}$

187 plastic vials containing stream water. When the streambed of the MC was dry, we inspected the

188 top $10 \mathrm{~cm}$ of streambed for individuals but could not find enough aquatic invertebrate biomass for

189 analysis. Ground-dwelling riparian invertebrates were searched for and manually caught within 2

$190 \mathrm{~m}$ of the stream edge at random intervals along the outer side of each reach (i.e., not in the space

191 between the two channels), and stored in dry $50 \mathrm{~mL}$ plastic vials. Predatory taxa were stored

192 separately. Macroinvertebrates were left alive for ca. $8 \mathrm{~h}$ to void stomach contents, then

193 identified, sorted to family, and stored at $-20^{\circ} \mathrm{C}$ until analysis.

194 We collected potential basal organic matter (OM) sources as material collected from at 195 least 3 locations along the sampling reach of each stream and then combined into a single sample 
196 (see Jardine et al., 2014). Leaves of riparian plants (separated by species) and aquatic mosses

197 were collected from living plants. Coarse particulate organic matter (CPOM) and fine particulate

198 organic matter (FPOM) were collected directly from the stream. Periphyton was collected as

199 epilithon scrubbed with a wire brush and rinsed from cobbles. All OM samples were stored at -

$20020^{\circ} \mathrm{C}$ until analysis.

$201 \quad$ All moss and CPOM samples were briefly thawed and then triple-rinsed with distilled

202 water. Terrestrial plant, moss and CPOM samples were air-dried at $60^{\circ} \mathrm{C}$ for 72 hours and then

203 mechanically ground and homogenized. Periphyton and FPOM samples were centrifuged for 12

204 min to separate out inorganic matter. Periphyton, FPOM, and invertebrate samples were freeze-

205 dried for 48 hours in a Lyovac GT 2-E lyophilizer (STERIS GmbH, Hürth, Germany).

206 Invertebrate samples were finely chopped and homogenized after drying. We individually

207 weighed $\sim 0.5-1.5 \mathrm{mg}$ OM, periphyton, and animal samples and combusted them in a Vario

208 PYRO Cube elemental analyzer (Elementar Analysensysteme GmbH, Langenselbold, Germany)

209 connected to an IsoPrime isotope ratio mass spectrometer (GV Instruments Ltd., Wythenshave,

210 U.K.) for measurement of total $\mathrm{C}$ content, total $\mathrm{N}$ content, $\delta^{13} \mathrm{C}$ and $\delta^{15} \mathrm{~N}$. Reference materials for

$211 \delta^{13} \mathrm{C}$ and $\delta^{15} \mathrm{~N}$ derived from NBS 19, L-SVEC, IAEA-N-1 and IAEA-N-2 were provided by

212 Biogeochemical Laboratories, Indiana University. Analytical uncertainty was $0.1 \%$ for $\delta^{13} \mathrm{C}$ and

$213 \quad 0.2 \%$ for $\delta^{15} \mathrm{~N}$.

214 Data analysis

215 We used a before-after control-impact design (BACI) to test whether macroinvertebrate

216 community composition, diversity and organic matter standing stocks were affected by flow

217 intermittence. The RC was used as the control group. We also sought to characterize the

218 manipulation period itself to determine whether flow intermittence, or the resumption of natural 
219 flow following intermittence, would represent the major perturbation for the benthic ecosystem.

220 We thus split the data into 3 time periods: before the flow manipulation, during the flow

221 manipulation, and after the flow manipulation. Fixed factors for all following analyses were

222 based on the groups imposed by this structure (i.e., the different time periods, separated by site;

$223 \mathrm{MC}$ before, $\mathrm{RC}$ before, $\mathrm{MC}$ during, etc.).

To identify how community composition changed between channels over time, we

225 identified similarities among macroinvertebrate assemblages with non-metric multidimensional

226 scaling (nMDS) using Bray-Curtis dissimilarities. Mean density data were used in the analysis

227 (before $\mathrm{n}=13$; during $\mathrm{n}=15$; after $\mathrm{n}=6$ ). Taxa were pooled to lowest common taxonomic level

228 (family for insects; order for non-insects) and data were standardized by Wisconsin double

229 standardization. Taxa found in less than 3 samplings were excluded from analysis. We excluded

230 the August 30 sampling of the MC due to extremely low densities (all taxa mean $<1$ individuals).

231 We then assessed whether community composition differed between channels and across the

232 different time periods using permutational multivariate analysis of variance (PERMANOVA).

233 We assessed which taxa contributed most to differences across groups using indicator species

234 analysis (ISA). The nMDS and PERMANOVA analysis were conducted using the package vegan

235 (Oksanen et al., 2017), and ISA was conducted using the package indicspecies (Cáceres \&

236 Legendre, 2009) in R 3.4.2 ( $\mathrm{R}$ core team 2013).

237 We calculated several biological indices for testing differences in aquatic biodiversity

238 between the two channels over time. We summarized assemblages using total density

239 (individuals $\mathrm{m}^{-2}$ ), density of rheophilic taxa, taxonomic richness (s), and proportion of ' $\mathrm{s}$ '

240 composed of rheophilic taxa (\%). Rheophilic taxa were identified using rheophilic/rheobiont

241 current preference following Schmedtje \& Colling, (1996) and Buffagni et al., (2018). Indices 
242 summarizing organic matter measurements included density (AFDM per unit area) and C:N

243 ratios (total $\mathrm{C}$ content/total $\mathrm{N}$ content). We tested whether differences existed across means in

244 biological and organic matter indices of all groups (i.e., before, during, and after time periods in

245 each channel) using analysis of variance (ANOVA). We then compared pairwise differences in

246 the indices between the two channels within the specific before, during, and after manipulation

247 time periods using Tukey's Honest Significant Difference (HSD) tests. All tests were conducted

248 using base packages in R 3.4.2 ( $\mathrm{R}$ core team 2013).

249 We also assessed changes in the trophic base of macroinvertebrate food webs over time.

250 Here, we used the Bayesian mixing model SIAR (Parnell et al., 2010) to produce probability

251 distributions of the dietary contributions of basal food resource groups to (i) aquatic

252 macroinvertebrates and (ii) predatory riparian invertebrates. CPOM and periphyton were included

253 as potential sources in the models for aquatic macroinvertebrates. FPOM was excluded as a

254 potential food source due to very low $\delta^{15} \mathrm{~N}$ values relative to aquatic consumers (see Philips et al.,

255 2005; Jardine et al., 2013). Riparian prey (ants; Formicidae) and aquatic prey (aquatic

256 macroinvertebrates) were included as potential sources in the models for riparian predators. We

257 did not include additional prior information on diet proportions because sources in each mixing

258 model were equal to the number of tracers (Fry, 2013; Brett, 2014). We ran the model separately

259 for each time period in each channel (see BACI structure, above). CPOM (Kruskal-Wallis tests; p

$260=0.25$ to 0.57$)$, periphyton $(\mathrm{p}=0.28$ to 0.46$)$, and riparian prey $(\mathrm{p}=0.21$ to 0.64$) \delta^{13} \mathrm{C}$ and $\delta^{15} \mathrm{~N}$

261 values did not differ significantly over time and were set as averages for each channel for all

262 sampling times. Aquatic prey $\delta^{13} \mathrm{C}$ and $\delta^{15} \mathrm{~N}$ were set as averages for each time period in each

263 channel. Trophic enrichment factors were set at $0.4 \pm 1.0 \%$ for $\delta^{13} \mathrm{C}$ and $2.2 \pm 1.2 \%$ for $\delta^{15} \mathrm{~N}$

264 (Post, 2002; McCutchan et al., 2003). Each model was set to run 500,000 times, with the first 
50,000 iterations discarded. We present the upper and lower quartiles of model results together

266 with the median. We describe results as differing where the median is higher than the upper

267 quartile, or lower than the lower quartile, of another distribution. All models were created using

268 the SIAR package (Parnell et al., 2010) in R 3.4.2 (R Core Team, 2012).

\section{Data Availability Statement}

270 The datasets analysed during the current study are available in the Dryad repository,

$271<$ https://doi.org/10.5061/dryad.xksn02vcr> (Siebers et al., 2020).

\section{Results}

Flow intermittency, physical environment, and chemistry

274 Both streams began flowing in early April (Fig. 2b, d). The reference channel (RC) then flowed

275 continuously through the sampling period (Fig. 2b). A brief (1 day) first drying event in the 276 manipulation channel (MC) occurred on 10 June, 25 days after installation of the flow diversion

277 (Fig. 2d). More extended drying events (> 1 day in duration) then occurred from 30 June to 19

278 September in MC (Fig. 2d). During this time, MC dried 8 times for an average of 7.6 days (sd

$279 \pm 5.5$ ) each. 6 flow events also occurred in MC during the manipulation period, driven by rainfall

280 events greater than $15 \mathrm{~mm} \mathrm{~d}^{-1}$ (cross correlation test, $\mathrm{p}>0.20$ with 2-5 day lag period) (Fig. 2).

281 Electrical resistance readings in $\mathrm{RC}$ were largely stable (Dickey-Fuller test, $\mathrm{p}=0.29$ ) during the

282 manipulation period (Fig. 2), and were not significantly affected by rain events (cross correlation

283 test, $\mathrm{p}<0.13$ ). After removal of the flow diversion on 20 September, MC resumed flow for the

284 remaining sampling period (Fig. 2d). 
were consistent $\left(3.4 \pm 2.0^{\circ} \mathrm{C}\right)$ before and after the flow manipulation, but increased substantially

$288\left(13.0 \pm 2.7^{\circ} \mathrm{C}\right)$ during the manipulation period (Fig. 2e). Dry channel readings (i.e. air

289 temperatures) averaged $13.9 \pm 2.2^{\circ} \mathrm{C}$, but water temperature during the flow manipulation was

290 only slightly lower $\left(11.9 \pm 2.9^{\circ} \mathrm{C}\right)$. Water chemistry was mostly consistent across both channels

291 and seasons (Table 1). An exception was total phosphorus concentrations, which became higher

292 in MC after the onset of flow intermittency than in RC (Table 1).

\section{Biotic responses before/after flow manipulation}

294 Macroinvertebrates assemblages were differentiated by channel and time period (Fig. 3a). An

295 early seasonal (spring) community characterized by Limoniidae and Simuliidae (ISA p $=0.002$ )

296 was common at both channels before the flow manipulation. Communities in RC diverged from

297 July into a later seasonal assemblage that remained consistent until November, and differentiated

298 from the spring assemblage with higher densities of large predatory dipterans (Muscidae,

299 Empididae) and rheophilic Ephemeroptera (Baetidae) and Plecoptera (Perlodidae, Leuctridae),

300 particularly Nemouridae (ISA p $=0.03$ ) (Fig. 3b). Communities in MC diverged from both the

301 spring assemblages and RC following the flow manipulation (Fig. 3a). Communities in MC

302 remained dissimilar from $\mathrm{RC}$ following resumption of natural flow (October onwards).

303 Communities in MC during and after the manipulation were differentiated from RC with higher

304 densities of Oligochaeta, Hydracarina, and Pediciidae, although Pediciidae also occured in RC

305 from October (ISA p $=0.008)($ Fig. 3b).

Macroinvertebrate densities (ANOVA, $\mathrm{p}<0.001)$, densities of rheophilic taxa $(\mathrm{p}<$

$0.001)$, taxa richness $(\mathrm{p}<0.001)$, and the proportion of rheophilic taxa $(\mathrm{p}<0.001)$ all differed

similarly across channels and time periods. In spring prior to flow manipulation,

309

macroinvertebrate densities (Tukey's HSD, $p=0.99)$, densities of rheophilic taxa $(p=0.94)$, taxa 
310 richness $(\mathrm{p}=0.99)$, and the proportion of rheophilic taxa $(\mathrm{p}=1)$ were similar in RC and MC (Fig.

311 4). During the flow manipulation, macroinvertebrate densities ( $p<0.001$ ), densities of rheophilic

$312 \operatorname{taxa}(\mathrm{p}<0.001)$, taxa richness $(\mathrm{p}<0.001)$, and the proportion of rheophilic taxa $(\mathrm{p}<0.001)$ were

313 lower in MC (Fig. 4). Macroinvertebrate densities $(\mathrm{p}<0.009)$, densities of rheophilic taxa $(\mathrm{p}<$

$3140.001)$, taxa richness $(\mathrm{p}<0.001)$, and the proportion of rheophilic taxa $(\mathrm{p}=0.04)$ all remained

315 lower in MC after natural flow resumption ( $\mathrm{p}=0.009)$ (Fig. 4).

316 Changes in benthic organic matter

317 Standing stocks of coarse benthic organic matter (BOM) differed between channels and time

318 periods (ANOVA, $\mathrm{p}=0.02$ ). Coarse $\mathrm{BOM}$ density was higher in $\mathrm{RC}$ during spring, prior to the

319 flow manipulation (Tukey’s HSD, $\mathrm{p}=0.03$ ) (Fig. 5a). However, standing stocks of coarse BOM

320 were similar in $\mathrm{MC}$ and $\mathrm{RC}$ both during $(\mathrm{p}=0.99)$ and after the flow manipulation $(\mathrm{p}=0.99)$

321 (Fig. 5a). CPOM C:N ratios also differed between channels and time periods (ANOVA, $\mathrm{p}=$

322 0.02). CPOM C:N ratios were higher in MC than RC prior to the flow manipulation (Tukey's

323 HSD, $\mathrm{p}=0.04)$, but were similar in both channels during (0.50) and after the flow manipulation

$324(\mathrm{p}=0.99)($ Fig. 5b). Standing stocks of periphyton were similar in both channels across all time

325 periods (ANOVA, $\mathrm{p}=0.16$ ) (Fig. 5c). The $\mathrm{C}: \mathrm{N}$ ratios of periphyton also were similar in both

326 channels across all time periods (ANOVA, p = 0.45) (Fig. 5d).

327 Trophic base of food webs

328 Estimated assimilation of CPOM by macroinvertebrate primary consumers (range of median

329 estimations; 0.47 to 0.73 ) was generally higher than that of periphyton (0.27 to 0.50$)$ (Fig. 6a, c).

330 Prior to the flow manipulation, estimated assimilation of periphyton was higher in MC (median

331 estimation; 0.40) than RC (0.27) (Fig. 6c). During the flow manipulation, estimated assimilation 
332 of periphyton was similar in RC (0.29) but increased in MC (0.50) (Fig. 6c). After resumption of

333 natural flow, estimated assimilation of periphyton remained higher in $\mathrm{MC}(0.53)$ than $\mathrm{RC}(0.32)$

334 (Fig. 6c).

335 All riparian predators collected were hunting spiders (Lycosidae, Gnaphosidae,

336 Agelenidae). Prior to the flow manipulation, estimated assimilation of aquatic prey was similar in

337 both MC (median estimation; 0.25) and RC (0.34) (Fig. 6d). Estimated assimilation of aquatic

338 prey did not change notably during the flow manipulation, but was higher across both MC (0.48)

339 and RC (0.49) following resumption of natural flow (Fig. 6d), with concurrent reductions in the

340 estimated assimilation of terrestrial prey (Fig. 6b).

\section{Discussion}

342 Intermittency effects on the physical and chemical environment

343 Data from the electrical resistance sensors indicated that the reference channel (RC) had a

344 relatively stable flow regime, with continuous summer and autumn flow following spring

345 snowmelt. This flow regime likely reflects a source mix of snowmelt, rainfall and glacial melt

346 (Brown et al., 2003; Paillex et al., 2020). The relatively low variability of electrical resistance

347 readings in RC, combined with a corresponding lack of variability in biological indices in RC,

348 suggest that there were also likely no substantial floods or spates within RC during the year. In

349 contrast, the flow diversion caused discharge in the manipulated channel (MC) to be driven solely

350 by large rainfall events. The lag in response between rain and flow events further indicates that

351 alluvial sediments were not saturated while MC was dry (Malard et al., 1999). The manipulated

352 flow regime was thus analogous to pulsed, ephemeral regimes of many dryland and

353 Mediterranean streams (Costigan et al., 2017). Further, MC had minimal groundwater upwelling 
354 (Paillex et al., 2020) and highly permeable underlying alluvium (Tockner et al., 1997), similar to

355 primary drivers of flow intermittency in other montane catchments (Jaeger \& Olden, 2012; Sando $356 \&$ Blasch, 2014).

357 We observed distinct increases in temperature with increased flow intermittency. In Val

358 Roseg, higher temperatures are characteristic of intermittent channels with rainfall and snowmelt-

359 dominated flow regimes (Paillex et al., 2020). Relatively stable and lower temperatures in RC

360 indicate a possible groundwater or glacial water source, as these streams tend to be colder with

361 more stable thermal regimes (Brown et al., 2003; Paillex et al., 2020). However, both channels

362 had low silicate and alkalinity levels throughout the experiment, indicating that groundwater was

363 not a major water source (Malard et al., 1999; Malard et al., 2006). We conclude that the stream

364 is usually fed by glacial melt via the glacial moraine during summer, with occasional rainfall

365 inputs (see Paillex et al., 2020). Dry channel readings (i.e., air temperature) account for much of

366 the temperature increase in MC. However, low flows, ponding, and drying also may have

367 increased the effect of solar radiation on water and sediment temperatures as the experiment

368 progressed during summer and autumn (Gómez et al., 2017).

369 In contrast to temperature, the chemical environment of MC was largely unaffected by

370 increased flow intermittency. The exception was higher total phosphorus $(\mathrm{P})$ concentrations in

371 MC than in RC during and after the manipulation period. High total $\mathrm{P}$ concentrations are

372 characteristic of glacier-fed streams due to resuspension of glacial flour (Tockner et al., 1997).

373 While organic $\mathrm{P}$ also can be released by an increase in organic matter decomposition, we did not

374 observe any change in reactive nutrient forms that might indicate higher biogeochemical

375 processing rates after the flow manipulation (e.g., SRP, $\mathrm{NO}_{3}$; von Schiller et al., 2017). Alpine

376 soils and sediments are relatively young in a geological context and thus tend to have low 
377 bioavailable nutrient concentrations (Schlesinger \& Bernhardt, 2013). Biogeochemical processes

378 might thus be restricted overall by low nutrient and organic matter concentrations. For example,

379 streams in Val Roseg have relatively low sediment respiration rates compared with non-alpine

380 streams (Logue et al., 2004; Robinson et al., 2016a). Much of the P released through glacial melt

381 is also mineral-bound and not readily available to microbial communities (Hodson et al., 2004).

382 Consequently, it is likely that total $\mathrm{P}$ concentrations increased due to increased retention and

383 evapo-concentration of fine particulate material during the flow reduction period.

\section{Intermittency effects on macroinvertebrate assemblages}

385 In this study, we observed large reductions in both density and diversity of benthic

386 macroinvertebrates with increased flow intermittency. As above, relatively stable electrical

387 resistance readings and biological indices in RC over time suggest that no substantial

388 perturbations occurred in RC in response to floods or spates. Patterns in MC thus more closely

389 resemble community responses to supra-seasonal drought (i.e., unpredictable in timing and

390 duration) than periodic or seasonal drying (see Lake, 2003). Alpine benthic communities may

391 thus be adapted more toward winter as opposed to summer drying periods (Lytle \& Poff, 2004),

392 i.e., towards predictably long rather than shorter but unpredictable drying periods (e.g. Sánchez-

393 Montoya et al. 2018). There was also no increase in density with the initial flow reduction (i.e.,

394 after the flow manipulation but before consistent channel drying) (Online resource Fig. S.1)

395 suggesting that there was little concentration of macroinvertebrates into surface water refugia

396 (Acuña et al., 2005; Dewson et al., 2007; Walters \& Post, 2011). Streams in Val Roseg are

397 mostly high gradient with limited sub-surface storage, limiting the occurrence and permanence of

398 pools (Malard et al., 2000; Robinson \& Matthaei, 2007; Paillex et al., 2020). Most of the benthic

399 taxa observed here also have been recorded in the hyporheos of Val Roseg (Malard et al., 2003a; 
400 b), which may have provided an alternative drying refuge. However, we did not observe rapid

401 recolonization of MC following rewetting, suggesting that hyporheic water tables may have

402 become depleted during intermittency and thereby reduced the value of the hyporheic zone as a

403 refuge (Datry, 2012; Vander Vorste et al., 2016a). We would need to conduct comprehensive

404 hyporheic sampling to confirm this hypothesis, however.

Macroinvertebrate densities in MC did not recover to those observed in RC following

406 resumption of natural flow, yet densities in MC following flow resumption were still higher than

407 those during the end of the flow manipulation. Some level of recolonization via drift (Doretto et

408 al., 2018), emergence from the hyporheic zone (Vander Vorste et al., 2016), and/or oviposition

409 (Cauvie-Fraunié et al., 2015) thus likely occurred. We did not measure these processes directly

410 throughout the study period. However, data on macroinvertebrate drift collected during removal

411 of the flow manipulation (Online resource Fig. S.2) shows that drift patterns differed between

$412 \mathrm{MC}$ and RC. In particular, Perlodidae were abundant in MC drift but not RC drift following flow

413 resumption (Online resource Fig. S.2b). However, densities in MC following flow resumption

414 were almost entirely non-rheophilic (Fig. 3). Instead of the hyporheic zone not representing a

415 refuge, as discussed above, we suggest that this pattern reflects emergence from the hyporheic

416 zone directly into drift, and therefore to downstream communities rather than the previously dry

417 channel. In fact, non-rheophilic taxa (e.g., Chironomidae) often have more cohorts during the

418 year when compared with uni- or semi-voltine rheophilic taxa (e.g., Baetidae) (Burgherr \& Ward,

419 2001). We suggest that aerial dispersal therefore represents the most likely source of

420 recolonization at MC (Alther et al., 2019).

421 The timing of drying (here June-July) coincides with the emergence and egg-laying

422 period of aquatic macroinvertebrates with aerial adult stages (Burgherr \& Ward, 2001; Leys et 
423 al., 2017). An increase in densities at this time in RC, particularly for rheophilic taxa (Online

424 resource Fig. S.1), further suggests a summer oviposition peak for taxa with aerial dispersal. The 425 timing of flow resumption (here autumn) thus likely excluded this summer cohort in MC. In 426 addition, adults of rheophilic taxa likely would have avoided MC due to a lack of surface water

427 habitats, even if surface water was present after rain events (Bogan \& Boersma, 2012; Doretto et

428 al., 2018). Distribution patterns in alpine streams are often strongly driven by aerial dispersal

429 (Cauvy-Fraunié et al., 2015; Alther et al., 2019). Reductions in both density and diversity in MC

430 are thus likely due to both peaks in emergence immediately prior to drying, and low

431 recolonization from aerial sources while the channel was dry. The lack of a summer-growing

432 cohort for many taxa would also partially explain why density and diversity did not recover in

433 MC following flow resumption.

Despite the high prevalence of flow intermittency in Val Roseg (Robinson et al., 2016a;

435 Paillex et al., 2020), it appears that alpine macroinvertebrates may not be resistant to seasonal

436 cycles of drying (as in, e.g., dryland or Mediterranean rivers; see Bogan et al., 2017). Although

437 many alpine taxa are resistant to low temperatures and low channel stability (Milner et al., 2017),

438 these adaptation mechanisms may not result in co-tolerance to stream drying (see Vander Vorste

439 et al., 2016b). Limited sub-surface storage in alpine headwaters might limit the hyporheic zone as

440 a refuge and other resistance mechanisms during dry periods, as described above. For instance,

441 the low recolonization following flow resumption in $\mathrm{MC}$ also suggests that desiccation-resistant

442 taxa are rare in alpine headwaters (Bogan et al., 2017) and that increasing flow intermittency

443 might thus exclude desiccation-sensitive taxa (Arscott et al., 2010; Datry, 2012). In the Swiss

444 Alps, similar genetic diversity in mayfly populations of perennial and intermittent streams

445 (Shama et al., 2011) infers that aerial dispersal and source-sink dynamics can provide strong 
446 resilience to disturbance (Bogan et al., 2017). Our results suggest that the seasonality and timing

447 of flow intermittency is another major determinant of whether this resilience pathway occurs. Our

448 results indicate that resilience mechanisms are intrinsically tied to the geomorphological context

449 of channels and the life-history characteristics of the taxa present, rather than a general trend

450 across intermittent fluvial systems (Robson et al., 2011; Bogan et al., 2017).

$451 \quad$ Intermittency effects on organic matter and stoichiometry

452 We observed no change in periphyton biomass or $\mathrm{C}: \mathrm{N}$ ratios with experimental flow

453 intermittency. Periphyton biomass in alpine environments is often limited overall by frequent

454 scouring and bed movement, low temperatures, and low inorganic nutrient availability (Uehlinger

455 et al., 2009). In addition, drying of epilithic biofilms might strongly reduce autotrophic biomass

456 and enzymatic activity rather than overall biomass or bulk stoichiometric ratios (Timoner et al.,

457 2012). Thus drying may not have affected bulk periphyton biomass to a measurable extent in MC

458 (e.g., Piano et al., 2019a).

We also observed no change in the quantity or $\mathrm{C}: \mathrm{N}$ ratios of particulate organic matter

460 with flow manipulation. These patterns contradict our hypothesis that terrestrial organic matter

461 would accumulate in stream channels in the absence of downstream transport (e.g., Acuña et al.,

462 2004) and increase in $\mathrm{C}: \mathrm{N}$ ratios due to leaching of non-structural compounds and low rates of

463 microbial conditioning (Datry et al., 2018). Litter inputs in Val Roseg show autumnal peaks due

464 to the presence of deciduous trees (Zah \& Uehlinger, 2001) and both RC and MC may thus have

465 only received low rates of litterfall during summer, perhaps insufficient to increase coarse BOM

466 standing stocks. During the experimental period, several rainfall events also resulted in pulsed

467 flow events within MC and may have transported benthic organic matter downstream (Larned et

468 al., 2010). Rain events might also rehydrate microbial biofilms (Sabater et al., 2016), thus 
469 potentially compensating for the effects of drying on organic matter stoichiometry. For instance,

470 rates of microbially-mediated biogeochemical processes are often highest in intermittent rivers

471 and streams during rewetting events (Larned et al., 2010; von Schiller et al., 2017). Thus, the

472 consistent quantity and stoichiometry of POM and periphyton here might reflect the averaging of

473 drying and rewetting effects, rather than a true lack of variation.

474 Intermittency effects on the trophic base of food webs

475 Mixing models estimated higher periphyton assimilation in MC than RC after the onset of flow

476 intermittency, matching patterns previously seen in Val Roseg (Siebers et al., 2019). It was

477 posited that decreasing CPOM lability in dry channels was the mechanism driving increased

478 periphyton assimilation (Siebers et al., 2019). As described above, we observed no change in

479 CPOM C:N ratios with experimental flow intermittency. Consequently, macroinvertebrate diets

480 may have instead shifted due to changes in biotic interactions (Holomuzki et al., 2010). Indeed,

481 differences in species composition between channels post-manipulation were largely associated

482 with densities of invertebrate predators (Perlodidae, Empididae, Muscidae), but also grazers

483 (Nemouridae). Reduced predation pressure might increase herbivore activity and/or reduce refuge

484 use, leading to increased grazing on exposed stone surfaces where periphyton is common

485 (Schmitz et al., 2004). In addition, a reduction in grazer densities might reduce intraspecific

486 competition for labile algal resources (e.g., McNeely et al., 2007). An overall decrease in

487 macroinvertebrate density, particularly for obligate grazers such as Baetidae, is likely to reduce

488 resource competition. Drying may also have affected detritivores more strongly than grazers

489 (Corti et al., 2011), although the taxa contributing most to differences between RC and MC post-

490 manipulation did not include any terrestrial OM specialists (e.g. shredders). Thus, it appears 
491 probable that increasing flow intermittency reduced density-dependent interaction pressures upon

492 primary consumers, allowing them to specialize on higher-quality food resources.

Riparian spiders assimilated approximately 25 to $49 \%$ of their $\mathrm{C}$ and $\mathrm{N}$ from aquatic

macroinvertebrates, which is similar to estimates from other intermittent running waters (Sanzone

et al., 2003; Paetzold et al., 2005). However, the estimated increase of aquatic prey in the diet of riparian spiders at $\mathrm{MC}$ after flow manipulation is surprising, given that the density of aquatic macroinvertebrates and rheophilic taxa (i.e., including many taxa here with emergent adult

498 stages) both declined substantially. Aquatic prey availability typically limits both the biomass

499 (Greenwood \& McIntosh, 2010) and diversity (McCluney \& Sabo, 2012; Corti \& Datry 2014) of

500 riparian arthropods. As with the aquatic taxa, competition might thus have decreased if spider

501 densities were lower. Alternatively, aquatic or semi-aquatic prey may have become easier to 502 access with flow reduction or cessation (McIntosh et al., 2017). Spiders also might shift diets to 503 favour aquatic emergents if they cannot obtain enough water from terrestrial prey, i.e. under arid

504 or drought conditions (McCluney \& Sabo, 2009). While riparian spiders typically have small

505 home range areas (c. < $20 \mathrm{~m}$ from streams; e.g., Briers et al., 2005), we cannot exclude the 506 possibility that spiders fed across both MC and RC, especially given the similar assimilation

507 estimates across both. Consequently, further catchment-scale sampling is necessary to fully

508 clarify how flow intermittency affects riparian spider diets in alpine landscapes.

509 Conclusions

510 We conducted our experiment within a single channel, which limits the conclusions we can draw

511 as to how flow intermittency might affect entire alpine fluvial networks. Further, the increase in

512 flow intermittency we induced was artificial and might affect benthic communities differently to

513 natural drying events. For example, the removal of the water associated with the manipulation 
514 might have removed some cues associated with declining flow, e.g., chemical stimuli (Lund et al.

515 2016). However, it was 25 days between when we began manipulating flow and when drying first

516 occurred. Flow was reduced in the MC during this time but still occurring via discharge from

517 local bank storage, hyporheic upwellings, and rainfall events (pers. obs., the authors). For

518 comparison, flow pulses are often shorter than 25 days in the intermittent headwater streams of

519 Val Roseg (Paillex et al., 2020). In addition, the length of time that we continued sampling after

520 flow resumption (approx. 1.5 months) is usually sufficient time for re-establishment of

521 macroinvertebrate fauna in intermittent systems (Larned et al. 2010). Further, as discussed above

522 for organic matter dynamics, the frequency and duration of rewetting events is an important

523 driver of IRES ecosystem structure and function (e.g., Shumilova et al. 2019). We might thus

524 observe markedly different patterns under different rainfall regimes. Despite this, the changes we

525 saw in density, richness, and composition of macroinvertebrate communities with increased flow

526 intermittency were clear and persisting. We thus conclude that the patterns we saw here are likely

527 to occur in other alpine streams experiencing increased summer flow intermittency. Given that

528 densities and diversity did not recover by the end of the snow-free season, whether the effects of

529 our flow manipulation persist into the following year is likely to be an important, as yet unknown

530 indicator as to the long-term impacts of flow intermittency in alpine streams.

531 Today, alpine streams are most likely to dry in winter, when water is largely "locked up"

532 in snow and ice reserves, although summer and autumn flow intermittency is also common

533 (Paillex et al., 2020). In the near future, decreasing summer rainfall and loss of glacial melt is

534 predicted to increase summer and autumn drying of streams (IPCC, 2014). Our results suggest

535 that the onset of flow intermittency in summer will result in a loss of habitat for cohorts of

536 rheophilic taxa. In a landscape context, increased flow intermittency may thus favour 
537 multivoltine or overwintering lineages, reducing genetic diversity within catchments (Shama et

538 al., 2011; Leys et al., 2017). High habitat heterogeneity among headwater streams also drives

539 high beta diversity across alpine catchments (Karaus et al., 2013; Robinson et al., 2016b; Alther

540 et al., 2019). Further, reduced densities of benthic macroinvertebrates in MC were more

541 dependent on periphyton. With increased flow intermittency, reduced invertebrate shredding of

542 leaf litter (Corti et al., 2011) might further lead to less bioavailable and more highly pulsed

543 subsidies to downstream reaches (Battin et al., 2008; Larned et al., 2010). An increase in flow

544 intermittency across alpine catchments might thus fundamentally alter both biodiversity and

545 ecosystem function at the landscape scale.

\section{Acknowledgements}

547 Funding for this project was provided through Eawag Discretionary Funds for Research, the 548 Ernst Göhner foundation, Gelbert foundation, and Department of Nature and Environment,

549 Canton Graubünden. We thank Marion Caduff, Larissa Schädler, Jorrit Mesman, and Christa

550 Jolidon for assistance in the field and laboratory. We thank Christian Ebi for development of the

551 electrical resistance loggers. We thank Serge Robert for analysis of EA-IRMS samples, and the

552 AuA Lab at Eawag for analysis of water chemistry. We thank Gemeinde Pontresina for road

553 access to Val Roseg. We are grateful to Lucrezia and Wolfgang Pollak-Thom, and staff of the

554 Hotel Restaurant Roseg Gletscher, for their hospitality. Several anonymous reviewers and the

555 Editor provided suggestions that greatly improved the quality of this article.

556 References 
Acuña, V., A. Giorgi, I. Muñoz, U. R. S. Uehlinger \& S. Sabater, 2004. Flow extremes and benthic organic matter shape the metabolism of a headwater Mediterranean stream. Freshwater Biology 49: 960-971.

560 Acuña, V., I. Muñoz, A. Giorgi, M. Omella, F. Sabater \& S. Sabater, 2005. Drought and postdrought recovery cycles in an intermittent Mediterranean stream: structural and functional aspects. Journal of the North American Benthological Society 24: 919-933.

563 Alther, R., C. Thompson, B. Lods-Crozet \& C. T. Robinson, 2019. Macroinvertebrate diversity and rarity in non-glacial Alpine streams. Aquatic Sciences 81: 42.

Arscott, D. B., S. Larned, M. R. Scarsbrook \& P. Lambert, 2010. Aquatic invertebrate community structure along an intermittence gradient: Selwyn River, New Zealand. Journal of the North American Benthological Society 29: 530-545.

Battin, T. J., L. A. Kaplan, S. Findlay, C. S. Hopkinson, E. Marti, A. I. Packman, ... \& F. Sabater, 2008. Biophysical controls on organic carbon fluxes in fluvial networks. Nature Geoscience 1: 95.

571 Bauernfeind, E. \& U.H. Humpesch, 2001. Die Eintagesfliegen Zentraleuropas (Insecta: Ephemeroptera): Bestimmung und Ökologie. Verlag des Naturhistorischen Museums Wien, Vienna.

Bogan, M. T. \& K. S. Boersma, 2012. Aerial dispersal of aquatic invertebrates along and away from arid-land streams. Freshwater Science 31: 1131-1144.

576 Bogan, M. T., E. T. Chester, T. Datry, A. L. Murphy, B. J. Robson, A. Ruhi, ... \& J. E. Whitney, 2017. Resistance, resilience, and community recovery in intermittent rivers and ephemeral 
streams. In Intermittent Rivers and Ephemeral Streams: Ecology and Management (pp. 349-376). Academic Press.

580

Brown, L. E., D. M. Hannah \& A. M. Milner, 2003. Alpine stream habitat classification: an alternative approach incorporating the role of dynamic water source contributions. Arctic, Antarctic, and Alpine Research 35: 313-322.

Brown, L. E., K. Khamis, M. Wilkes, P. Blaen, J. E. Brittain, J. L. Carrivick, ... \& S. Hainie, 2018. Functional diversity and community assembly of river invertebrates show globally consistent responses to decreasing glacier cover. Nature Ecology \& Evolution 2: 325.

Buffagni, A., D. G. Armanini, M. Cazzola, J. Alba-Tercedor, M. J. López-Rodríguez, J. Murphy, L. Sandin \& A. Schmidt-Kloiber, 2019. Dataset "Ephemeroptera". www.freshwaterecology.info - the taxa and autecology database for freshwater organisms, version 7.0 (accessed on 05.04.2019).

Burgherr, P. \& J. V. Ward, 2001. Longitudinal and seasonal distribution patterns of the benthic fauna of an alpine glacial stream (Val Roseg, Swiss Alps). Freshwater Biology 46: 17051721.

Cáceres, M. D. \& P. Legendre, 2009. Associations between species and groups of sites: indices and statistical inference. Ecology 90: 3566-3574.

Cauvy-Fraunié, S., R. Espinosa, P. Andino, D. Jacobsen \& O. Dangles, 2015. Invertebrate metacommunity structure and dynamics in an Andean glacial stream network facing climate change. PloS one 10: e0136793. 
598 Cauvy-Fraunié, S., P. Andino, R. Espinosa, R. Calvez, D. Jacobsen \& O. Dangles, 2016.

599 Ecological responses to experimental glacier-runoff reduction in alpine rivers. Nature $600 \quad$ Communications 7: 12025.

601 Chapin, T. P., A. S. Todd \& M. P. Zeigler, 2014. Robust, low- cost data loggers for stream 602 temperature, flow intermittency, and relative conductivity monitoring. Water Resources $603 \quad$ Research 50: 6542-6548.

604 Corti, R., T. Datry, L. Drummond \& S. T. Larned, 2011. Natural variation in immersion and 605 emersion affects breakdown and invertebrate colonization of leaf litter in a temporary 606 river. Aquatic Sciences 73: 537.

607 Corti, R. \& T. Datry, 2014. Drying of a temperate, intermittent river has little effect on adjacent 608 riparian arthropod communities. Freshwater Biology 59: 666-678.

609 Costigan, K., C. Leigh, E. Sauquet, M. Kennard, T. Datry \& A. J. Boulton, 2017. Flow regimes in 610 intermittent rivers and ephemeral streams. In Intermittent Rivers and Ephemeral Streams: $611 \quad$ Ecology and Management (pp. 51-78). Academic Press.

612 Datry, T, 2012. Benthic and hyporheic invertebrate assemblages along a flow intermittence 613 gradient: effects of duration of dry events. Freshwater Biology 57: 563-574.

614 Datry, T., A. Foulquier, R. Corti, D. von Schiller, K. Tockner, C. Mendoza-Lera, ... \& B. Gücker, 615 2018. A global analysis of terrestrial plant litter dynamics in non-perennial waterways. $616 \quad$ Nature Geoscience 11: 497.

617 Dewson, Z. S., A. B. James \& R. G. Death, 2007. Invertebrate responses to short- term water 618 abstraction in small New Zealand streams. Freshwater Biology 52: 357-369. 
619 Doretto, A., E. Piano, E. Falasco, S. Fenoglio, M. C. Bruno \& F. Bona, 2018. Investigating the role of refuges and drift on the resilience of macroinvertebrate communities to drying conditions: An experiment in artificial streams. River Research and Applications 34: 777785.

623 Eiseler, B., 2010. Taxonomie für die Praxis: Bestimmungshilfen - Makrozoobenthos (1).

624 Landesamt für Natur, Umwelt und Verbraucherschutz Nordrhein, Westfalen, 625 Recklinghausen.

626 Fell, S. C., J. L. Carrivick \& L. E. Brown, 2017. The multitrophic effects of climate change and 627 glacier retreat in mountain rivers. BioScience 67: 897-911.

628 Gabbud, C., C. T. Robinson \& S. N. Lane, 2019. Sub-basin and temporal variability of macroinvertebrate assemblages in Alpine streams: when and where to sample?. Hydrobiologia 830: 179-200.

631 Gómez, R., M. I. Arce, D. S. Baldwin \& C. N. Dahm, 2017. Water physicochemistry in 632 intermittent rivers and ephemeral streams. In Intermittent Rivers and Ephemeral Streams

634 Greenwood, M. J. \& A. R. McIntosh, 2010. Low river flow alters the biomass and population 635 structure of a riparian predatory invertebrate. Freshwater Biology 55: 2062-2076.

636 Harjung, A., E. Ejarque, T. Battin, A. Butturini, F. Sabater, M. Stadler \& J. Schelker, 2019. 637 Experimental evidence reveals impact of drought periods on dissolved organic matter 638 quality and ecosystem metabolism in subalpine streams. Limnology and Oceanography 639 64: 46-60. 
640 Hodson, A., P. Mumford \& D. Lister, 2004. Suspended sediment and phosphorus in proglacial 641 rivers: bioavailability and potential impacts upon the $\mathrm{P}$ status of ice- marginal receiving 642 waters. Hydrological Processes 18: 2409-2422.

643 Holomuzki, J. R., J. W. Feminella \& M. E. Power, 2010. Biotic interactions in freshwater benthic 644 habitats. Journal of the North American Benthological Society 29: 220-244.

645 Hotaling, S., D. S. Finn, J. Joseph Giersch, D. W. Weisrock \& D. Jacobsen, 2017. Climate 646 change and alpine stream biology: progress, challenges, and opportunities for the future. $647 \quad$ Biological Reviews 92: 2024-2045.

648 Huss, M. \& R. Hock, 2018. Global-scale hydrological response to future glacier mass loss. $649 \quad$ Nature Climate Change 8: 135.

650 IPCC, 2014. Climate change 2014: Synthesis report. Cambridge University Press, Cambridge.

651 Jaeger, K. L. \& J. D. Olden, 2012. Electrical resistance sensor arrays as a means to quantify 652 longitudinal connectivity of rivers. River Research and Applications 28: 1843-1852.

653 Karaus, U., S. Larsen, H. Guillong \& K. Tockner, 2013. The contribution of lateral aquatic 654 habitats to insect diversity along river corridors in the Alps. Landscape Ecology 28: 17556551767.

656 Lake, P. S., 2003. Ecological effects of perturbation by drought in flowing waters. Freshwater $657 \quad$ Biology 48: 1161-1172.

658 Larned, S. T., T. Datry, D. B. Arscott \& K. Tockner, 2010. Emerging concepts in temporary$659 \quad$ river ecology. Freshwater Biology 55: 717-738. 
660 Leys, M., I. Keller, C. T. Robinson \& K. Räsänen, 2017. Cryptic lineages of a common alpine 661 mayfly show strong life- history divergence. Molecular Ecology 26: 1670-1686.

662 Logue, J. B., C. T. Robinson, C. Meier \& J. R. V. der Meer, 2004. Relationship between 663 sediment organic matter, bacteria composition, and the ecosystem metabolism of alpine 664 streams. Limnology and Oceanography 49: 2001-2010.

665 Lubini, V., S. Knispe \& G. Vinçon, 2012. Die Steinfliegen der Schweiz: Bestimmung und 666 Verbreitung. Fauna Helvetica 27. Université de Neuchâtel, Neuchâtel.

667 Lucht, W., 1998. Die Käfer Mitteleuropas, Bd. 15: 4. Supplementband. Gustav Fischer Verlag, $668 \quad$ Stuttgart.

669 Lund, J. O., S. A. Wissinger \& B. L. Peckarsky, 2016. Caddisfly behavioral responses to drying 670 cues in temporary ponds: implications for effects of climate change. Freshwater Science

671 35: 619-630.

672 Lytle, D. A. \& N. L. Poff, 2004. Adaptation to natural flow regimes. Trends in Ecology and $673 \quad$ Evolution 19: 94-100.

674 Malard, F., K. Tockner \& J. V. Ward, 1999. Shifting dominance of subcatchment water sources 675 and flow paths in a glacial floodplain, Val Roseg, Switzerland. Arctic, Antarctic, and $676 \quad$ Alpine Research 31: 135-150.

677 Malard, F., K. Tockner \& J. V. Ward, 2000. Physico-chemical heterogeneity in a glacial 678 riverscape. Landscape Ecology 15: 679-695. 
679 Malard, F., D. Ferreira, S. Dolédec \& J. V. Ward, 2003a. Influence of groundwater upwelling on 680 the distribution of the hyporheos in a headwater river flood plain. Archiv für $681 \quad$ Hydrobiologie 157: 89-116.

682 Malard, F., D. Galassi, M. Lafont, S. Doledec \& J. V. Ward, 2003b. Longitudinal patterns of 683 invertebrates in the hyporheic zone of a glacial river. Freshwater Biology 48: 1709-1725.

684 Malard, F., U. Uehlinger, R. Zah \& K. Tockner, 2006. Flood- pulse and riverscape dynamics in a 685 braided glacial river. Ecology 87: 704-716.

686 McCluney, K. E. \& J. L. Sabo, 2009. Water availability directly determines per capita 687 consumption at two trophic levels. Ecology 90: 1463-1469.

688 McCluney, K. E. \& J. L. Sabo, 2012. River drying lowers the diversity and alters the composition 689 of an assemblage of desert riparian arthropods. Freshwater Biology 57: 91-103.

690 McNeely, C., J. C. Finlay \& M. E. Power, 2007. Grazer traits, competition, and carbon sources to 691 a headwater- stream food web. Ecology 88: 391-401.

692 Milner, A. M., L. E. Brown \& D. M. Hannah, 2009. Hydroecological response of river systems to 693 shrinking glaciers. Hydrological Processes 23: 62-77.

694 Milner, A. M., K. Khamis, T. J. Battin, J. E. Brittain, N. E. Barrand, L. Füreder, ... \& A. J. 695 Hodson, 2017. Glacier shrinkage driving global changes in downstream systems. $696 \quad$ Proceedings of the National Academy of Sciences 114: 9770-9778.

697 Oksanen, J., F. B. Blanchet, M. Friendly, R. Kindt, P. Legendre, D. McGlinn, P. R. Minchin, R. 698 B. O’Hara, G. L. Simpson, P. Solymos, M. Henry, H. Stevens, E. Szoecs \& H. Wagner, 

project.org/package=vegan.

Paetzold, A., C. J. Schubert \& K. Tockner, 2005. Aquatic terrestrial linkages along a braidedriver: riparian arthropods feeding on aquatic insects. Ecosystems 8: 748-759.

Paillex, A., A. R. Siebers, C. Ebi, J. Mesman, \& C. T. Robinson, 2020. High stream intermittency in an alpine fluvial network: Val Roseg, Switzerland. Limnology and Oceanography 65:

Parnell, A. C., R. Inger, S. Bearhop \& A. L. Jackson, 2010. Source partitioning using stable isotopes: coping with too much variation. PloS one 5: e9672.

Piano, E., A. Doretto, E. Falasco, S. Fenoglio, L. Gruppuso, D. Nizzoli, ... \& F. Bona, 2019a. If Alpine streams run dry: the drought memory of benthic communities. Aquatic Sciences 81: 32 .

Piano, E., A. Doretto, E. Falasco, L. Gruppuso, S. Fenoglio \& F. Bona, 2019b. The role of recurrent dewatering events in shaping ecological niches of scrapers in intermittent Alpine streams. Hydrobiologia 841: 177-189. network in Switzerland. Hydrological Processes: An International Journal 21: 3146-3154. physico-chemistry and function of headwater streams in an Alpine glacial catchment. Aquatic Sciences 78: 327-341. 
719 Robinson, C. T., C. Thompson, B. Lods-Crozet \& R. Alther, 2016b. Chironomidae diversity in 720 high elevation streams in the Swiss Alps. Fundamental and Applied Limnology/Archiv 721 für Hydrobiologie 188: 201-213.

722 Robson, B. J., E. T. Chester \& C. M. Austin, 2011. Why life history information matters: drought 723 refuges and macroinvertebrate persistence in non-perennial streams subject to a drier 724 climate. Marine and Freshwater Research 62: 801-810.

725 Sabater, S., X. Timoner, C. Borrego \& V. Acuña, 2016. Stream biofilm responses to flow 726 intermittency: from cells to ecosystems. Frontiers in Environmental Science 4: 14.

727 Sánchez-Montoya, M. M., D. von Schiller, G. G. Barbera, A. M. Diaz, M. I. Arce, R. Del Campo 728 \& K. Tockner, 2018. Understanding the effects of predictability, duration, and spatial 729 pattern of drying on benthic invertebrate assemblages in two contrasting intermittent $730 \quad$ streams. PLoS One 13: e0193933.

731 Sando, R. \& K. W. Blasch, 2015. Predicting alpine headwater stream intermittency: a case study 732 in the northern Rocky Mountains. Ecohydrology \& Hydrobiology 15: 68-80.

733 Sanzone, D. M., J. L. Meyer, E. Martí, E. P. Gardiner, J. L. Tank \& N. B. Grimm, 2003. Carbon 734 and nitrogen transfer from a desert stream to riparian predators. Oecologia 134: 238-250.

735 Schlesinger, W. H. \& E. S. Bernhardt, 2013. Biogeochemistry: an analysis of global change. $736 \quad$ Academic press.

737 Schmedtje, U. \& M. Colling, 1996. Ökologische Typisierung der aquatischen Makrofauna. 738 Informationsberichte des Bayerischen Landesamtes für Wasserwirtschaf, Bayern. 
739 Schmitz, O. J., V. Krivan \& O. Ovadia, 2004. Trophic cascades: the primacy of trait- mediated $740 \quad$ indirect interactions. Ecology Letters 7: 153-163.

741 Shama, L. N., K. B. Kubow, J. Jokela \& C. T. Robinson, 2011. Bottlenecks drive temporal and 742 spatial genetic changes in alpine caddisfly metapopulations. BMC Evolutionary Biology

$743 \quad 11: 278$

744 Shumilova, O., D. Zak, T. Datry, D. von Schiller, R. Corti, A. Foulquier, ... \& M. I. Arce, 2019.

745 Simulating rewetting events in intermittent rivers and ephemeral streams: A global 746 analysis of leached nutrients and organic matter. Global Change Biology 25: 1591-1611.

747 Siebers, A. R., A. Paillex \& C. T. Robinson, 2019. Flow intermittency influences the trophic 748 base, but not the overall diversity of alpine stream food webs. Ecography 42: 1523-1535.

749 Siebers, A. R., A. Paillex, B. Misteli \& C. T. Robinson, 2020. Data for: Effects of an experimental increase in flow intermittency on an alpine stream. Dryad, dataset, $751 \quad<$ https://doi.org/10.5061/dryad.xksn02ver>

752 Tachet, H., M. Bournaud, P. Richoux \& P. Usseglio- Polatera, 2010 Invertébrés d'eau douce 753 systématique, biologie, écologie. CNRS Editions, Paris.

754 Timoner, X., V. Acuna, D. von Schiller \& S. Sabater, 2012. Functional responses of stream 755 biofilms to flow cessation, desiccation and rewetting. Freshwater Biology 57: 1565-1578.

756 Tockner, K., F. Malard, P. Burgherr, C. T. Robinson, U. Uehlinger, R. Zah \& J. V. Ward, 1997. 757 Physico-chemical characterization of channel types in a glacial floodplain ecosystem (Val Roseg, Switzerland). Archiv für Hydrobiologie 140: 433-463. 
759 Uehlinger, U., C. T. Robinson, M. Hieber \& R. Zah, 2009. The physico-chemical habitat

760 template for periphyton in alpine glacial streams under a changing climate. In Global

761 Change and River Ecosystems - Implications for Structure, Function and Ecosystem

$762 \quad$ Services (pp. 107-121). Springer.

763 Vander Vorste, R., F. Malard \& T. Datry, 2016a. Is drift the primary process promoting the

764 resilience of river invertebrate communities? A manipulative field experiment in an

765 intermittent alluvial river. Freshwater Biology 61: 1276-1292.

766 Vander Vorste, R., R. Corti, A. Sagouis \& T. Datry, 2016b. Invertebrate communities in gravel-

767 bed, braided rivers are highly resilient to flow intermittence. Freshwater Science 35: 164-

$768 \quad 177$.

769 von Schiller, D., S. Bernal, C. N. Dahm \& E. Martí, 2017. Nutrient and organic matter dynamics

770 in intermittent rivers and ephemeral streams. In Intermittent Rivers and Ephemeral

771 Streams: Ecology and Management (pp. 135-160). Academic Press.

772 Walters, A. W. \& D. M. Post, 2011. How low can you go? Impacts of a low- flow disturbance on 773 aquatic insect communities. Ecological Applications 21: 163-174.

774 Ward, J. V. 1994. Ecology of alpine streams. Freshwater Biology 32: 277-294.

775 Waringer J. \& W. Graf, 2011. Atlas der mitteleuropäischen Köcherfliegenlarven - Atlas of Central

776 European Trichoptera Larvae. Erik Mauch Verlag, Dinkelscherben.

777 Zah, R., \& U. Uehlinger, 2001. Particulate organic matter inputs to a glacial stream ecosystem in

778 the Swiss Alps. Freshwater Biology 46: 1597-1608. 
779 Zah, R., P. Burgherr, S. M. Bernasconi \& U. Uehlinger, 2001. Stable isotope analysis of 780 macroinvertebrates and their food sources in a glacier stream. Freshwater Biology 46:

$781 \quad 871-882$


783 Table 1: Mean water chemistry of the reference and manipulated channels across time periods. $<a^{\dagger}$ indicates that all samples were below 784 detection limits where $a=$ detection limit. $\mathrm{DOC}=$ dissolved organic carbon. $\mathrm{TN}=$ total nitrogen. $\mathrm{TP}=$ total phosphorus. $\mathrm{SRP}=$ soluble 785 reactive phosphate.

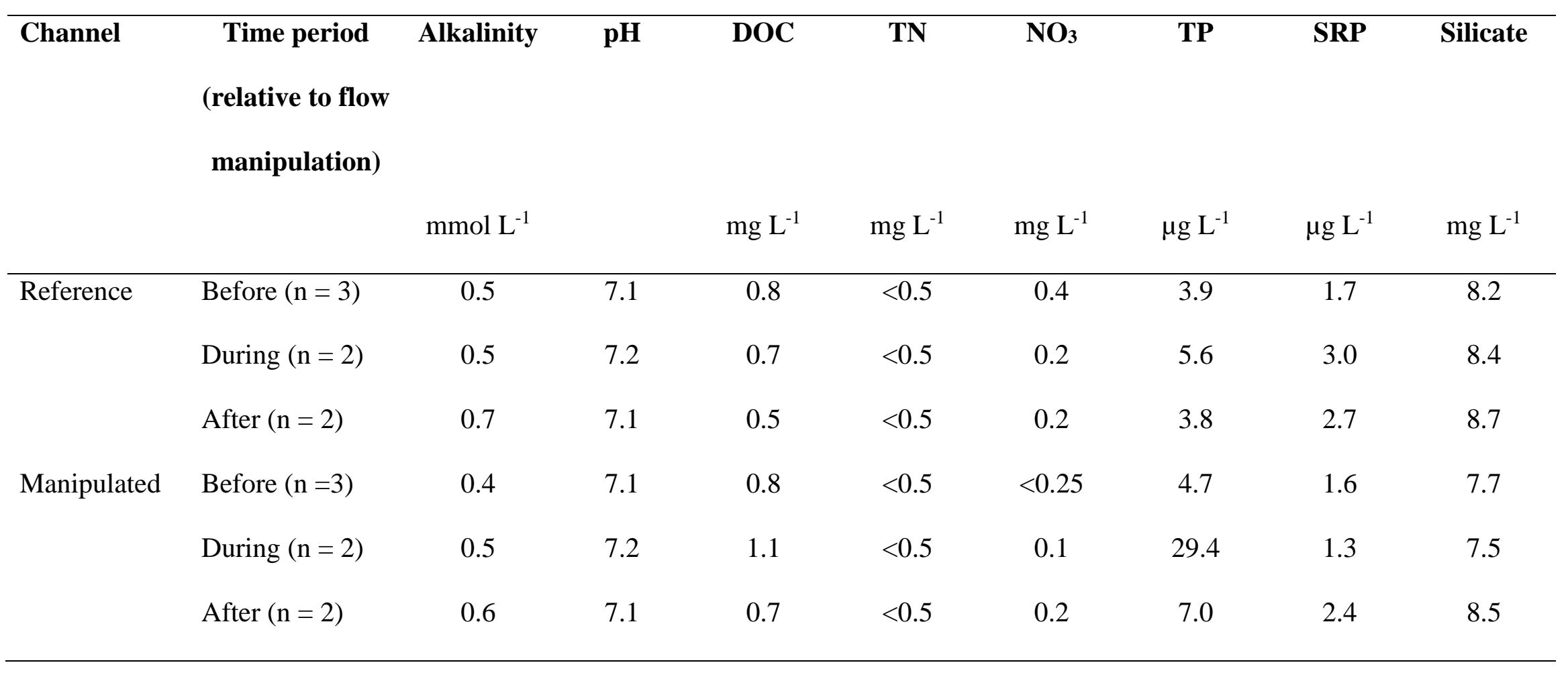


788 Figure 1: Photos of the two study channels. Shown are the reference channel $(a, b)$ and

789 manipulated channel (c, d) before (June 2018) and during (August 2018) the flow manipulation, 790 respectively.

791 Figure 2: Scatterplots showing trends over the sampling period (daily means) in (a) rainfall for

792 Val Roseg (data: Piz Corvatsch weather station, MeteoSwiss) as well as (b, d) relative

793 conductivity and (c, e) water temperature in the reference channel (RC) and manipulated channel

794 (MC), respectively. Relative conductivity values of zero indicate no liquid surface water

795 (freezing or drying). Dashed line indicates onset of regular drying periods (30 June) in MC. $\dagger$

796 indicates dates of sampling. Note log scale in (b) and (d). Break in data (October) indicates

797 logger maintenance period.

798 Figure 3: Non-metric multidimensional scaling (nMDS) plot of (a) macroinvertebrate

799 assemblages in the reference (green) and manipulated (orange) channels during the course of the

800 study based on standardized abundance data. Grouping of assemblages is based on time period

801 (before the flow manipulation, triangles; during the flow manipulation, circles; after natural flow

802 resumption, squares). (b) Relative influence of different taxa on the ordination. Taxa names are

803 slightly jittered for clarity.

804 Figure 4: Boxplots showing differences in (a) macroinvertebrate density, (b) density of rheophilic

805 taxa, (c) number of taxa (s), and (d) percentage of total taxa identified as rheophilic in the

806 reference (green) and manipulated (orange) channels. Grouping of data is based on time period

807 (before the flow manipulation, during the flow manipulation, and after natural flow resumption).

808 ind = individuals. $\mathrm{R}=$ reference channel. $\mathrm{M}=$ manipulated channel. Letters above plots $(\mathrm{a}, \mathrm{b}, \mathrm{c}$, 
809 d) indicate significantly similar group means (at $\mathrm{p}>0.05$ ) across channels in all time periods as 810 indicated by Tukey's HSD tests.

811 Figure 5: Boxplots showing differences in (a) coarse benthic organic matter (BOM), (b) BOM

812 C:N ratios, (c) periphyton biomass, and (d) periphyton $\mathrm{C}: \mathrm{N}$ ratios in the reference (green) and

813 manipulated (orange) channels. Grouping of data is based on time period (before the flow

814 manipulation, during the flow manipulation, and after natural flow resumption). $\mathrm{R}=$ reference

815 channel. $\mathrm{M}=$ manipulated channel. Letters above plots $(\mathrm{a}, \mathrm{b})$ indicate significantly similar group

816 means (at $\mathrm{p}>0.05$ ) across channels in all time periods as indicated by Tukey's HSD tests.

817 Figure 6: Estimated assimilation by invertebrate consumers (as proportions of total) of terrestrial 818 and aquatic basal resources in the reference (green) and manipulated (orange) channels.

819 Estimated contributions are shown as 25th percentile, median and 75th percentile of probability

820 distributions for (a) assimilation of coarse particulate organic matter (CPOM) by aquatic

821 macroinvertebrates, (b) assimilation of terrestrial invertebrates by riparian spiders, (c)

822 assimilation of periphyton by aquatic macroinvertebrates, and (d) assimilation of aquatic

823 macroinvertebrates by riparian spiders. Grouping of data is based on time period (before the flow

824 manipulation, during the flow manipulation, and after natural flow resumption). $\mathrm{R}=$ reference

825 channel. $\mathrm{M}=$ manipulated channel. 

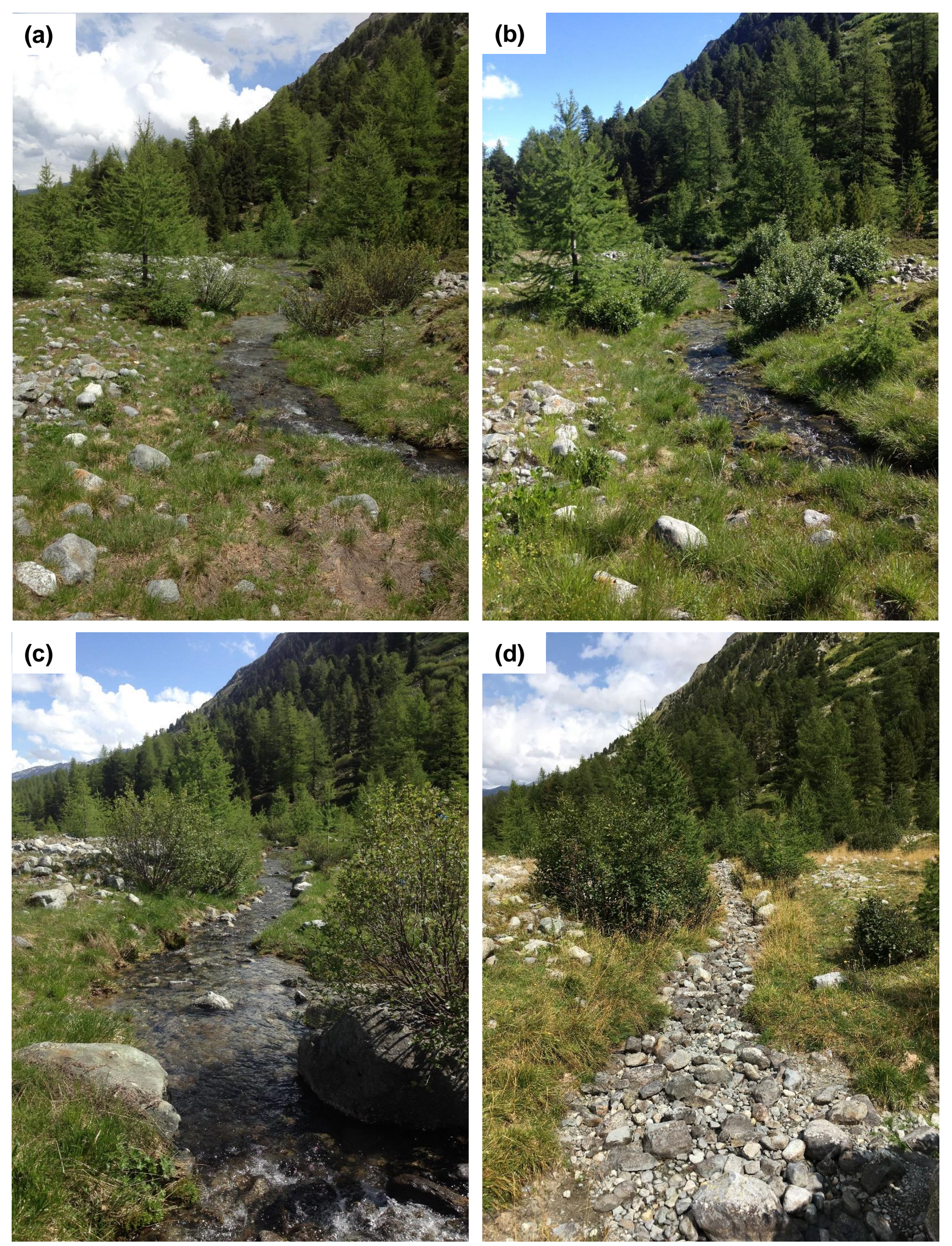


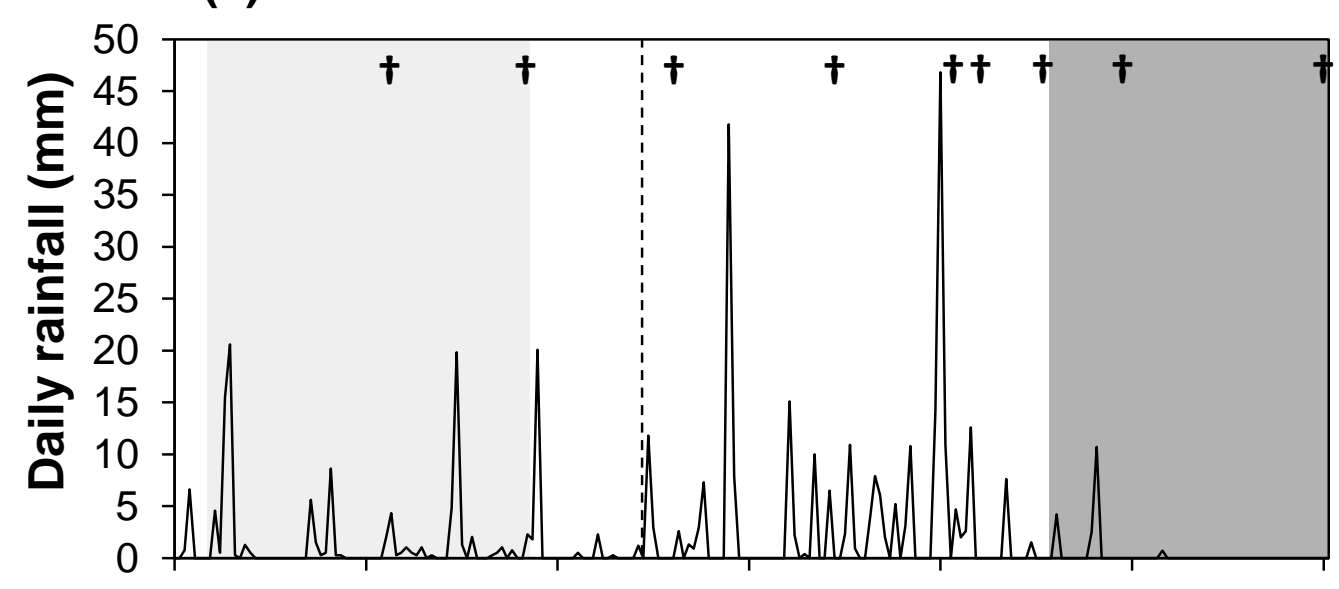

(b)

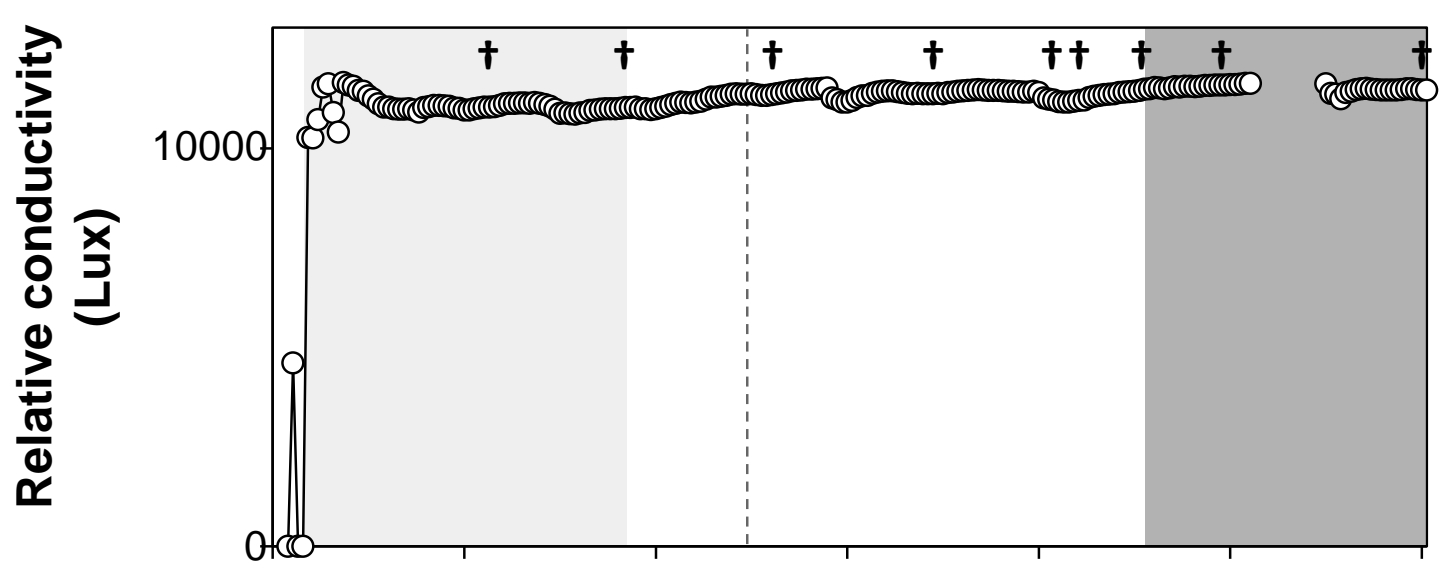

(c)
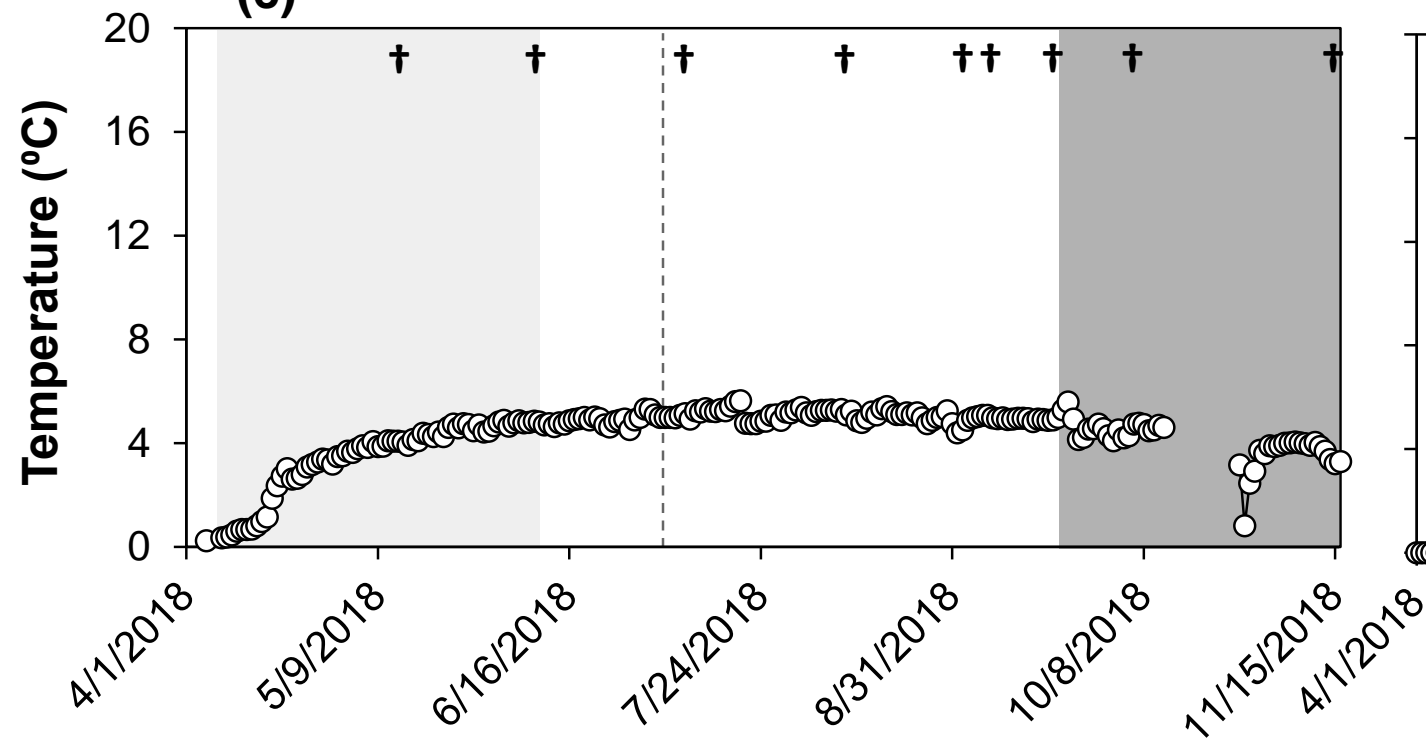

(d) Manipulated channel

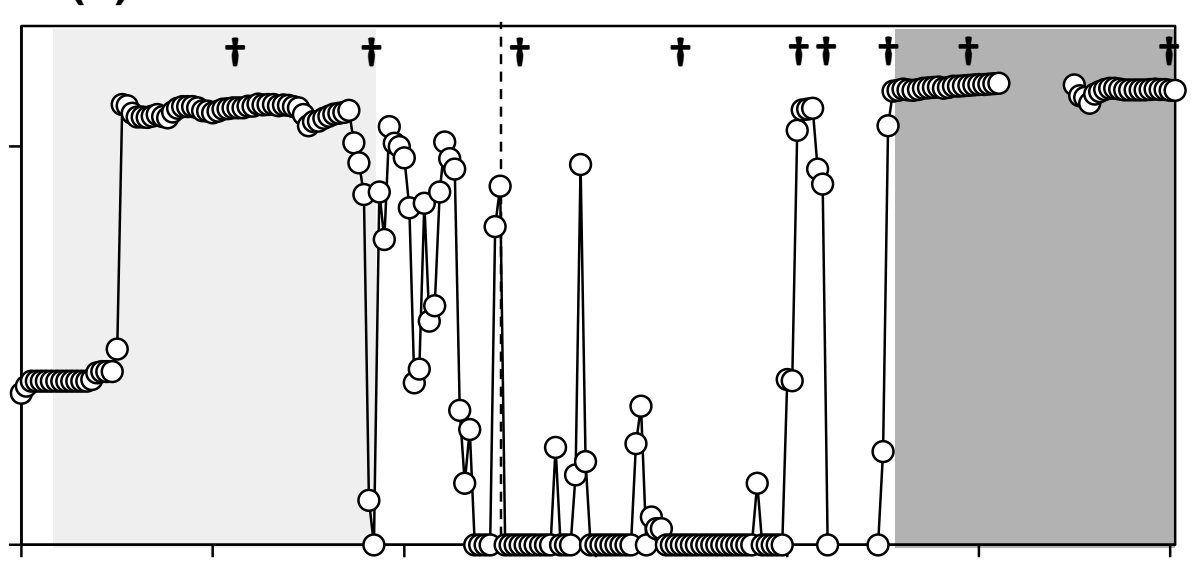

(e)

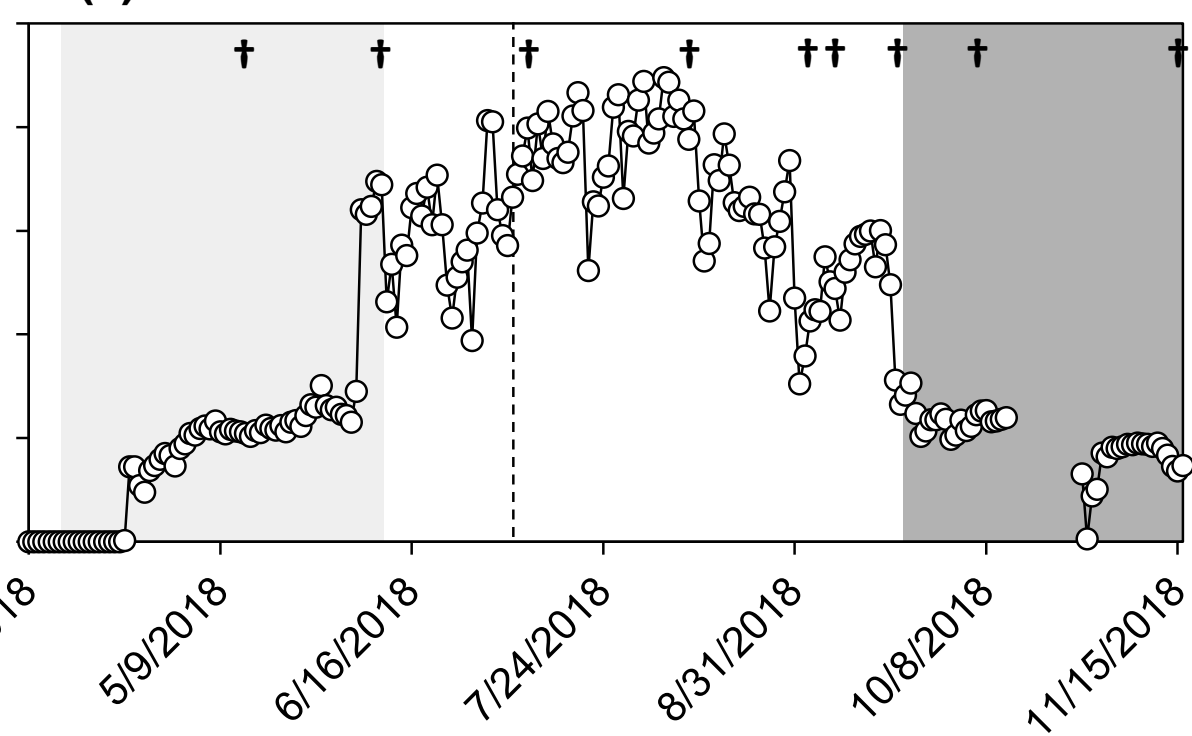

\section{Date}




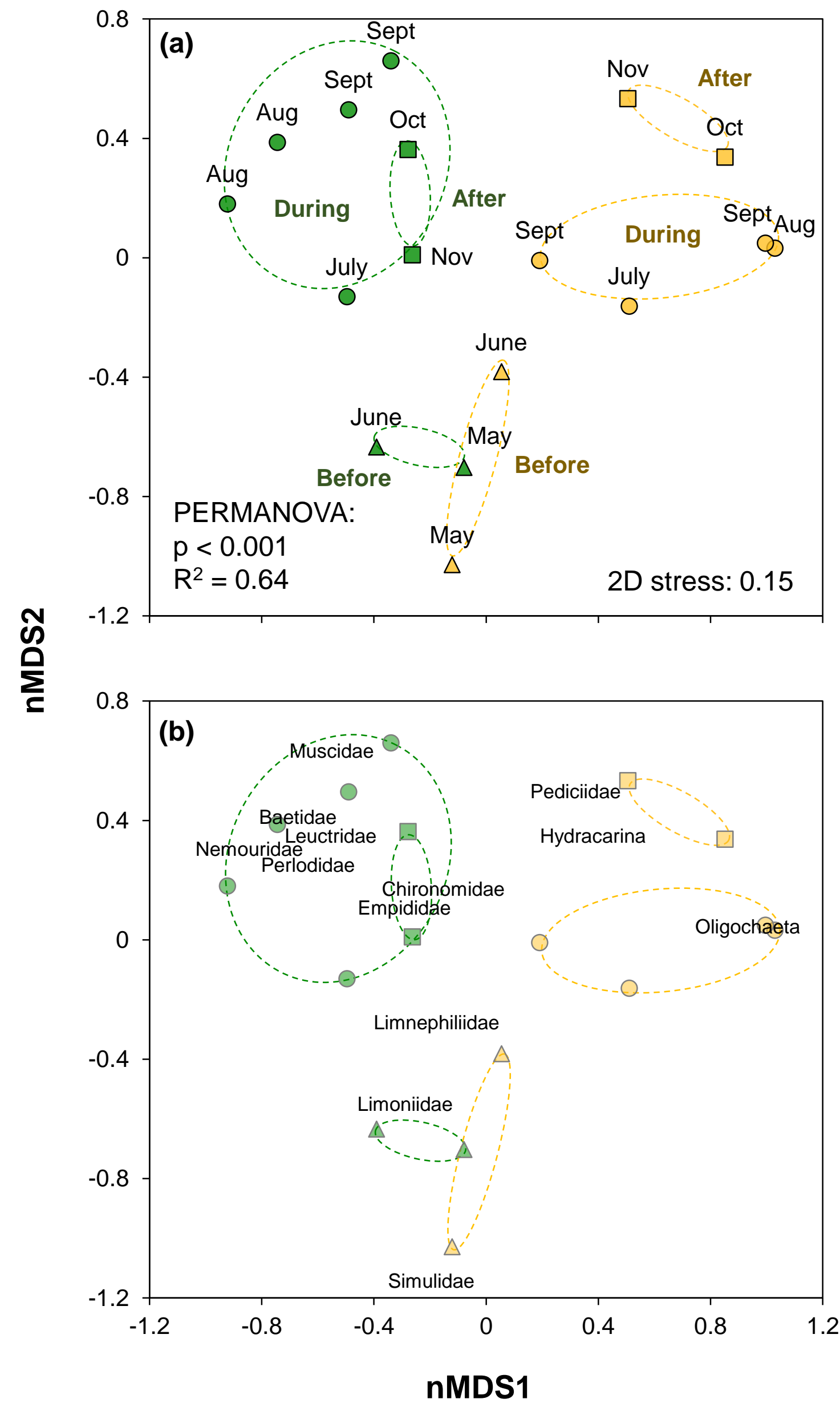



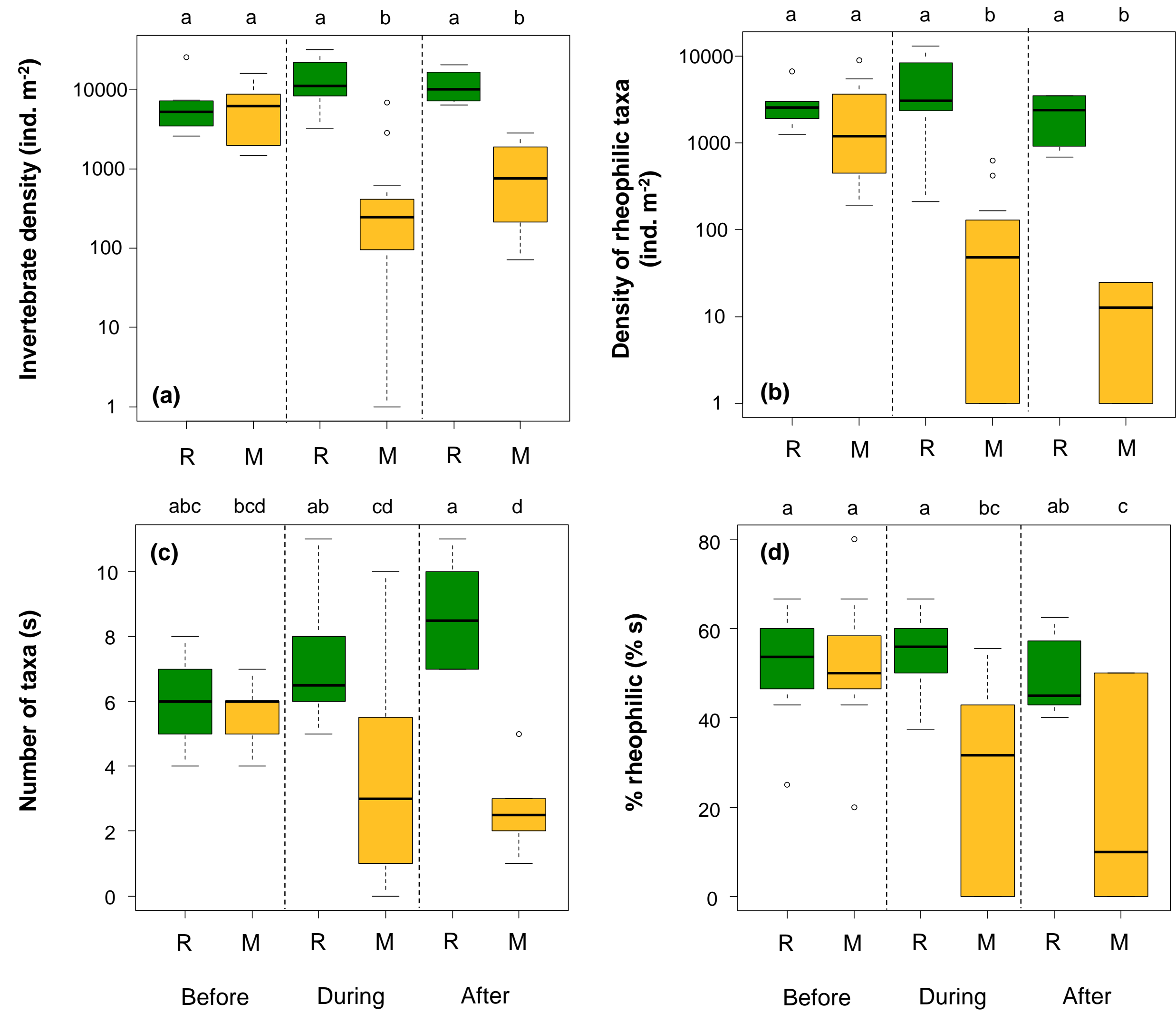

Sampling time relative to onset of flow intermittency 
Reference channel Manipulated channel
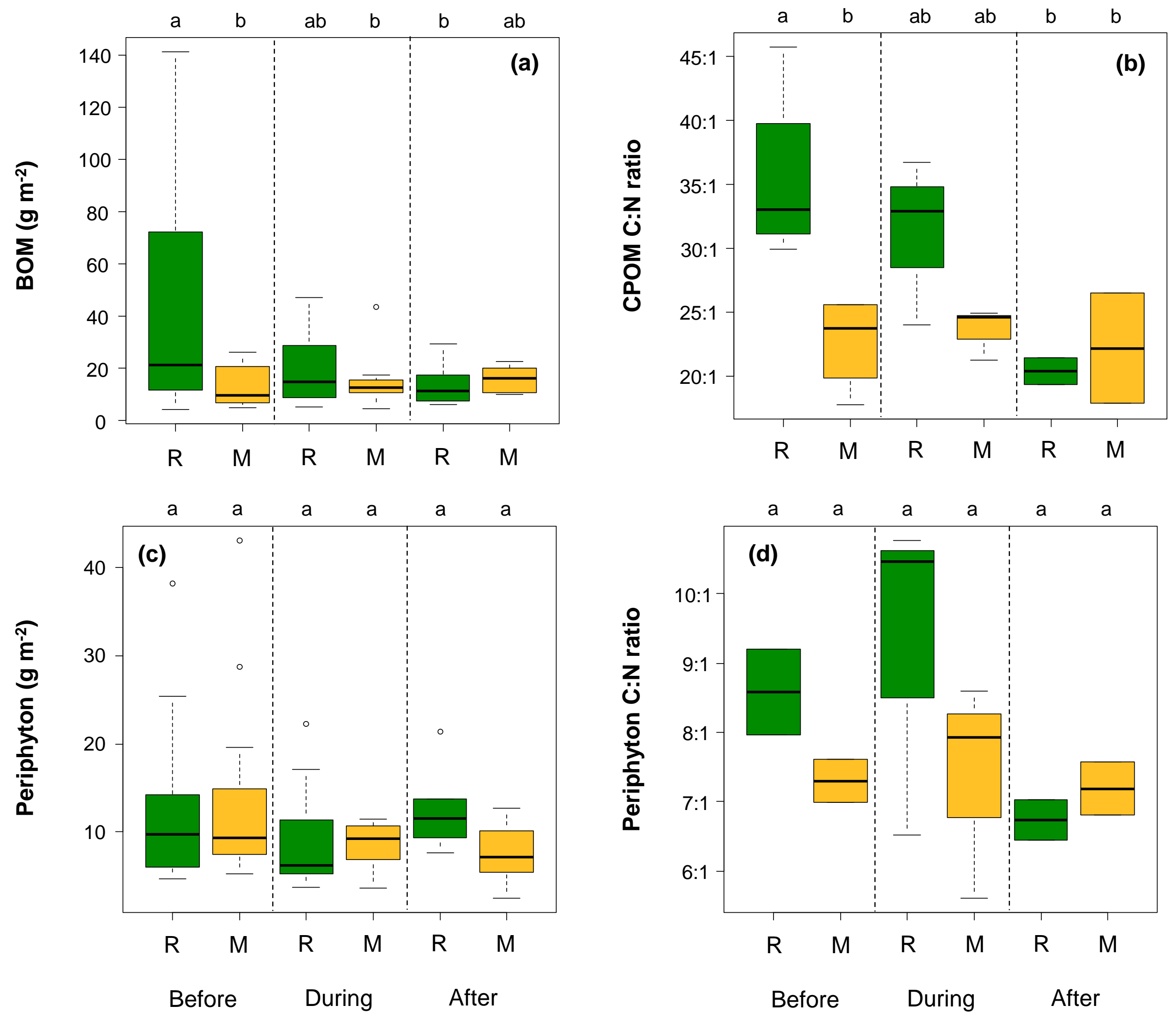

Sampling time relative to onset of flow intermittency 

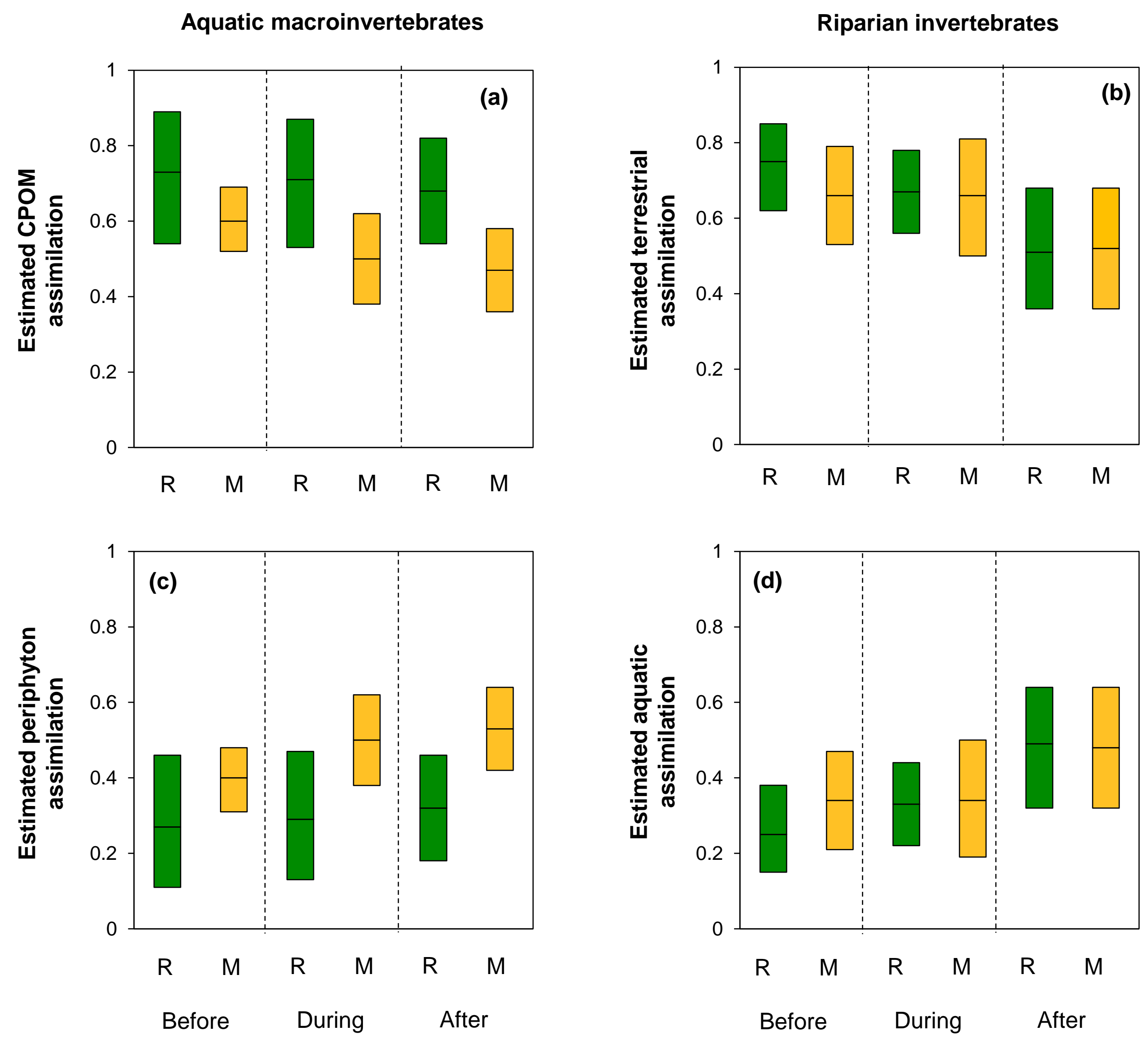

Sampling time relative to onset of flow intermittency 